\title{
LOS PRECIOS EN EUROPA \\ DURANTE LOS SIGLOS XVI Y XVII: ESTUDIO COMPARATIVO *
}

\author{
PABLO MARTIN ACEÑA \\ Universidad de Alcalá \\ y Fundación Empresa Pública
}

\begin{abstract}
RESUMEN
El objetivo principal de este trabajo ha sido proporcionar una medición lo más precisa posible del crecimiento de los precios en Europa entre 1500 y 1700. En primer lugar, se calcula un indice ponderado de precios para Castilla la Nueva homogéneo con el de otras regiones europeas, y así poder incorporar a nuestro estudio una de las áreas en las que tradicionalmente se ha centrado el examen de la revolución de los precios. A continuación, y empleando los instrumentos que suministra la moderna teoria monetaria, he tratado de ofrecer una interpretación del comportamiento de los precios sustentada en la teoría cuantitativa del dinero que, a mi entender, sigue proporcionando la mejor explicación de los cambios a largo plazo en el nivel absoluto de precios.
\end{abstract}

\section{ABSTRACT}

The main object of this paper is to present as precise a measure as possible of the growth of prices in Europe between 1500 and 1700. First, I calculate a weighted index of prices for Castilla la Nueva which is consistent with other European regions. This allows me to incorporate in the study one of the areas on which the study of the price revolution has traditionally centered. Second, employing the tools of modern monetary theory, I attempt to offer an interpretation of the behavior of prices based on the quantity theory of money. This theory, in my opinion, continues to offer the best explanation of the long-run changes in the absolute level of prices.

* Este trabajo ha sido presentado en distintos foros. Primero, en el Departamento de Economia de la Universidad de Toronto y, años más tarde, en el IV Congreso de la Asociación de Historia Económica celebrado en Alicante en diciembre de 1989. Ahora es el momento de agradecer los comentarios y observaciones de muchos colegas que lo leyeron y lo discutieron conmigo: Jon S. Cohen, Francisco Comin, Scott M. Eddie, Angel Garcia Sanz, Enrique Llopis, John H. Munro, Leandro Prados de la Escosura, David Reher, Felipe Ruiz Martín, Carles Sudrià, Piero Tedde, Gabriel Tortella y Bartolomé Yun. Empero, ninguno de ellos es responsable de los posibles errores y omisiones. 


\section{INTRODUCCION}

La inflación y deflación de precios que se produjo en Europa durante los siglos XVI y XVII ha sido uno de los temas que más ha captado la atención de los historiadores económicos. Su gran interés estriba en la inestimable información que proporcionan los precios acerca de la evolución general del periodo y en la trascendencia que tuvieron sus variaciones en el crecimiento y distribución de la renta europea entre 1500 y 1700 . El elevado número de estudios de que disponemos se ocupan básicamente de determinar la magnitud y establecer las causas del alza que tuvo lugar en el siglo XVI y del descenso en la centuria que sigue. Otros autores han centrado sus investigaciones en las consecuencias económicas de los movimientos de precios, esto es, de sus efectos sobre las tasas de inversión, ahorro y consumo, y sobre la distribución de la renta 1 .

El presente trabajo estudia la evolución de los precios en Europa durante los siglos XVI y XVII. En primer lugar hemos elaborado un índice ponderado para Castilla la Nueva, comparable a los que E. H. Phelps Brown y Sheila Hopkins, y Herman Van der Wee han construido para otras regiones europeas. A continuación se ofrece una medición, utilizando el análisis de regresión, de la inflación y deflación experimentadas por la economía europea entre 1500 y 1700 . Las series de precios estudiadas son las correspondientes a Alsacia, Amberes, Augsburgo, Sur de Inglaterra, Valencia, Viena y la elaborada por nosotros para Castilla la Nueva. Seguidamente se examinan los resultados obtenidos, se discute la magnitud de la "revolución de los precios» y se plantean diversas hipótesis sobre sus causas. En la última sección se estudia la evolución de los precios relativos en estas mismas regiones, calculando y analizando las relaciones de cambio interseccional. El trabajo se cierra con unas breves conclusiones.

\section{CASTILLA LA NUEVA: UN INDICE PONDERADO DE PRECIOS, 1501-1700}

En esta sección se ofrece el índice ponderado de precios que hemos calculado para Castilla la Nueva y se explica el procedimiento mediante el cual

1 Disponemos ahora de dos excelentes y utilisimos trabajos de sintesis sobre la llegada de metales preciosos americanos y sus efectos en la economia europea: Pieper (1987) y Ruiz Martín (19902). 
se ha obtenido ${ }^{2}$. Tomamos esta región, por su importancia y porque se dispone de series de precios más o menos completas que cubren un periodo de doscientos años. De otro lado, puesto que el grado de integración de los mercados de la España de los siglos XVI y XVII era probablemente muy escaso, el ceñirse a una región en lugar de tratar de elaborar un número índice nacional, permite depositar una mayor confianza en la nueva serie que presentemos. Por lo que se refiere al procedimiento seguido para el cálculo del índice ponderado de precios, hemos empleado el mismo método que ya utilizaran hace años Phelps Brown y Hopkins ${ }^{3}$, y que más tarde ha vuelto a utilizar Herman Van der Wee ${ }^{4}$.

Como se recordará, en su primer estudio para Inglaterra, Phelps Brown y Hopkins tomaron las series de precios de un conjunto de productos que agruparon en seis distintas categorias: productos farináceos, carne y pescado, mantequilla y queso, bebidas, alumbrado y combustible, y fibras textiles. Estos mismos grupos de mercancias fueron empleados más tarde por ambos autores al objeto de construir indices ponderados de precios para Alsacia, Augsburgo, Munich, Viena y Valencia ${ }^{5}$. El sistema de ponderación empleado para estas últimas regiones, aunque similar al que estos dos autores idearon para Inglaterra, lo modificaron de modo que tuviese en cuenta las peculiaridades de cada una de las economías para las cuales trataban de construir dichos indices ponderados ${ }^{6}$.

En nuestro trabajo hemos adoptado los seis grupos de mercancias propuestos por Phelps Brown y Hopkins. Los artículos individuales que integran cada uno de los grupos se recogen en el cuadro 1. La selección que hemos hecho ha estado dictada, esencialmente, por tres consideraciones. En primer lugar, se ha tratado de conservar la homogeneidad con la composición del conjunto de mercancías que sirvió para la elaboración de índices ponderados de precios para otras áreas europeas. En segundo término, hemos supuesto que estos catorce productos son representativos de lo que podríamos denominar la cesta de la compra del trabajador medio de Castilla durante los siglos XVI XVII ${ }^{7}$. Finalmente, nuestra elección ha estado limitada por la información de que disponemos sobre los precios. Así, esto último ha determinado, por ejemplo, los artículos que componen el grupo de textiles y también ha sido la

\footnotetext{
2 Los datos originales han sido tomados de Hamilton (1965, 2.* ed.).

3 Phelps Brown y Hopkins (1956).

- Van der Wee (1978).

5 Phelps Brown y Hopkins (1957).

- Phelps Brown y Hopkins (1959).

7 En favor de este argumento, véase Hamilton (1965).
} 


\section{CUADRO 1}

Grupos de mercancias y productos que componen la cesta de artículos de consumo esencial

\begin{tabular}{|c|c|c|c|}
\hline Grupos & Ponderaciones* & Productos & Ponderaciones * \\
\hline 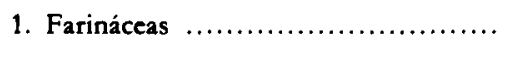 & 48,0 & $\begin{array}{l}\text { Trigo } \\
\text { Cebada }\end{array}$ & $\begin{array}{l}30,0 \\
18,0\end{array}$ \\
\hline 2. Carne y pescado $\ldots \ldots \ldots \ldots \ldots \ldots \ldots$ & 23,5 & $\begin{array}{l}\text { Vaca } \\
\text { Cordero } \\
\text { Gallinas } \\
\text { Sardinas } \\
\text { Pescado cecial }\end{array}$ & $\begin{array}{l}7,5 \\
7,5 \\
3,5 \\
2,5 \\
2,5\end{array}$ \\
\hline $\begin{array}{l}\text { 3. Queso } \ldots \ldots \ldots \ldots \ldots \ldots \ldots \ldots \ldots \ldots \ldots \ldots \ldots \ldots \ldots \ldots \ldots \ldots \ldots \ldots \ldots \ldots \ldots \\
\text { 4. Vino } \ldots \ldots \ldots \ldots \ldots \ldots \ldots \ldots \ldots \ldots\end{array}$ & $\begin{array}{r}3,0 \\
14,0\end{array}$ & . & \\
\hline 5. Combustible y alumbrado $\ldots . . . \ldots \ldots$ & 7,5 & $\begin{array}{l}\text { Aceite } \\
\text { Carbón vegetal } \\
\text { Velas de sebo }\end{array}$ & $\begin{array}{l}2,0 \\
3,5 \\
2,0\end{array}$ \\
\hline Textiles $\ldots \ldots \ldots \ldots \ldots \ldots \ldots \ldots$ & 4,0 & $\begin{array}{l}\text { Bramante } \\
\text { Cáñamo }\end{array}$ & $\begin{array}{l}2,0 \\
2,0\end{array}$ \\
\hline
\end{tabular}

* En porcentajes.

razón por la cual no incluimos la mantequilla entre los productos que integran nuestra muestra.

El índice calculado, y que se presenta en el cuadro 2, comienza en 1501 y termina en 1700 . Hemos de advertir que entre 1501 y 1550 no ha sido posible ponderar el índice con el mismo número de productos que aparecen en el 'cuadro 1. La razón es bien simple: Hamilton no ofrece datos sobre los precios de siete de los catorce artículos que forman nuestra muestra. Ante este problema cabían dos soluciones. La primera, no elaborar el índice ponderado para el período 1501-1550. Otra solución era tratar de aprovechar la limitada información disponible y calcular un índice ponderado con aquellos productos para los cuales sí existen precios, cuidando que su composición guardase cierta homogeneidad con el indice elaborado para los ciento cincuenta años siguientes. Optamos por esta última alternativa, utilizando las siguientes ponderaciones: el grupo de farináceas no registra cambios; el grupo de carne y pescado queda reducido a carne de vaca y cordero, con una ponderación de 11,75 cada uno de estos dos productos; los grupos tres y cuatro tampoco experimentan variación; el grupo cinco pasan a componerlo dos productos 
solamente, aceite y cera, con una ponderación de 5,75 cada uno; por fin el grupo de textiles se reduce a un solo artículo, lienzo, al que damos una ponderación de 4,0.

Otro problema que se planteó al construir el número índice fue la falta de precios para determinados productos de nuestra muestra en diversos años. Una inspección ciudadosa de las series que proporciona Hamilton revela que esta insuficiencia se presenta tanto en los primeros años del periodo como en los sucesivos. Antes de proceder a la elaboración del índice fue preciso, por tanto, llevar a cabo algunas estimaciones con objeto de completar nuestra información. Para llenar los huecos que teniamos, optamos por aplicar el mismo procedimiento que Phelps Brown y Hopkins emplearon en su trabajo cuando se enfrentaron al mismo problema ${ }^{8}$. Asi, hemos rellenado los huecos mediante interpolaciones o extrapolaciones lineales, partiendo del ajuste de líneas de regresión a los datos conocidos. Este método, aunque simple y no exento de dificultades, es el más apropiado para estos casos y el que se utiliza de modo más frecuente?

El problema más serio lo encontramos en el periodo 1601-1650, para el que no existen precios de tres de los productos que forman la muestra: carne de vaca, sardinas y queso. Con objeto de paliar esta falta, en la medida de lo posible, se adoptaron diversos expedientes. En el caso de la carne de vaca se utilizó la información indirecta que proporcionan los precios que tenemos sobre productos similares. En primer lugar elaboramos un indice de precios compuesto a partir de las series de precios de otros productos cárnicos que pueden ser considerados como sustitutivos de la carne de vaca: manos de cordero, cordero, carne de cordero, manteca y tocino salado. Una vez obtenido este índice calculamos su tendencia lineal y utilizamos los coeficientes obtenidos, es decir, el valor de la ordenada en el origen y de la pendiente, para extrapolar la serie original de precios de carne de vaca para el periodo que nos falta ${ }^{10}$. El procedimiento seguido para cubrir las observaciones sobre precios de sardinas entre 1600 y 1650 fue similar al anterior, sólo que empleando en este caso la serie de precios de pescado cecial. Por último, en el caso del queso las soluciones posibles eran dos: la primera, extrapolar la serie a partir de los coeficientes de la ecuación de ajuste a un nuevo número índice representativo de los precios de un conjunto de productos de granja; la segunda, hacer uso de la serie de precios del queso que Hamilton da para

\footnotetext{
8 Phelps Brown y Hopkins (1956), p. 28.

9 Hamilton, (1965), p. 273; y Van der Wee (1978), p. 62.

10 Un método alternativo hubiese sido utilizar la serie de precios de la carne de vaca de Castilla la Vieja.
} 


\section{CUADRO 2}

Indice de precios ponderado de Castilla la Nueva, 1551-1700

(Base: media 1601-1625 $=100$ )

\begin{tabular}{|c|c|c|c|c|c|c|c|c|c|c|}
\hline $\begin{array}{l}501 \\
502 \\
503 \\
504 \\
505 \\
506 \\
507 \\
508 \\
509 \\
510\end{array}$ & 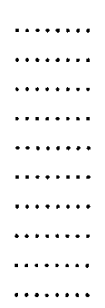 & $\begin{array}{l}18,75 \\
20,72 \\
20,13 \\
20,00 \\
23,05 \\
30,99 \\
31,00 \\
25,83 \\
17,97 \\
20,05\end{array}$ & $\begin{array}{l}1551 \\
1552 \\
1553 \\
1554 \\
1555 \\
1556 \\
1557 \\
1558 \\
1559 \\
1560\end{array}$ & 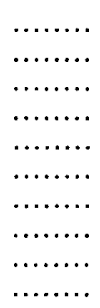 & $\begin{array}{l}37,04 \\
38,11 \\
36,95 \\
36,58 \\
37,65 \\
41,12 \\
47,54 \\
53,72 \\
53,48 \\
53,69\end{array}$ & $\begin{array}{l}1601 \\
1602 \\
1603 \\
1604 \\
1605 \\
1606 \\
1607 \\
1608 \\
1609 \\
1610\end{array}$ & $\begin{array}{l}\ldots \ldots . \\
\ldots \ldots . \\
\ldots \ldots . \\
\ldots \ldots . \\
\ldots \ldots . \\
\ldots . .\end{array}$ & $\begin{array}{r}80,26 \\
77,20 \\
78,04 \\
85,46 \\
101,27 \\
124,21 \\
124,13 \\
106,39 \\
96,29 \\
80,95\end{array}$ & $\begin{array}{l}1651 \\
1652 \\
1653 \\
1654 \\
1655 \\
1656 \\
1657 \\
1658 \\
1659 \\
1660\end{array}$ & $\begin{array}{ll}\ldots . & 162,01 \\
\ldots \ldots & 164,72 \\
\ldots . & 158,81 \\
\ldots . & 160,21 \\
\ldots . & 155,69 \\
\ldots & 161,68 \\
\ldots . & 136,98 \\
\ldots . & 149,43 \\
\ldots . & 158,91 \\
\ldots . & 170,34\end{array}$ \\
\hline $\begin{array}{l}511 \\
512 \\
513 \\
514 \\
515 \\
516 \\
517 \\
518 \\
519 \\
520\end{array}$ & $\ldots \ldots$ & $\begin{array}{l}18,35 \\
22,56 \\
22,75 \\
25,82 \\
21,37 \\
20,38 \\
22,31 \\
22,95 \\
20,51\end{array}$ & $\begin{array}{l}1561 \\
1562 \\
1563 \\
1564 \\
1565 \\
1566 \\
1567 \\
1568 \\
1569 \\
1570\end{array}$ & $\begin{array}{l}\ldots \ldots . \\
\ldots \ldots . \\
\ldots \ldots . \\
\ldots \ldots . \\
\ldots \ldots . \\
\ldots \ldots . \\
\ldots \ldots . \\
\ldots \ldots . \\
\ldots \ldots . \\
\ldots \ldots\end{array}$ & $\begin{array}{l}49,89 \\
53,16 \\
53,01 \\
55,93 \\
62,78 \\
60,91 \\
54,30 \\
60,27\end{array}$ & $\begin{array}{l}1611 \\
1612 \\
1613 \\
1614 \\
1615 \\
1616 \\
1617 \\
1618 \\
1619 \\
1620\end{array}$ & 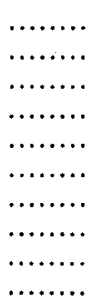 & $\begin{array}{r}80,25 \\
93,69 \\
90,49 \\
108,18 \\
107,71 \\
115,34 \\
119,97 \\
107,95 \\
99,05 \\
91,52\end{array}$ & $\begin{array}{l}1661 \\
1662 \\
1663 \\
1664 \\
1665 \\
1666 \\
1667 \\
1668 \\
1669 \\
1670\end{array}$ & 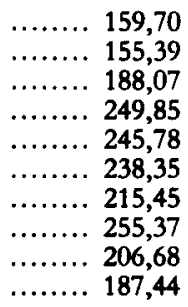 \\
\hline $\begin{array}{l}521 \\
522 \\
523 \\
524 \\
525 \\
526 \\
527 \\
528 \\
529 \\
530\end{array}$ & 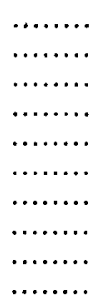 & $\begin{array}{l}25,72 \\
31,22 \\
25,92 \\
26,06 \\
27,46 \\
29,23 \\
26,35 \\
25,47 \\
28,45 \\
23,24\end{array}$ & $\begin{array}{l}1571 \\
1572 \\
1573 \\
1574 \\
1575 \\
1576 \\
1577 \\
1578 \\
1579 \\
1580\end{array}$ & 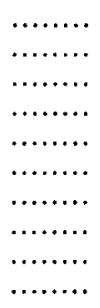 & $\begin{array}{l}50,05 \\
58,45 \\
57,23 \\
61,69 \\
70,20 \\
63,71 \\
68,08 \\
70,37 \\
71,61\end{array}$ & $\begin{array}{l}1621 \\
1622 \\
1623 \\
1624 \\
1625 \\
1626 \\
1627 \\
1628 \\
1629 \\
1630\end{array}$ & $\begin{array}{c}\cdots \cdots \\
\cdots \cdots \\
\cdots \cdots\end{array}$ & $\begin{array}{r}95,67 \\
96,36 \\
116,79 \\
113,49 \\
109,78 \\
115,01 \\
123,15 \\
129,93 \\
131,49 \\
131,28\end{array}$ & $\begin{array}{l}1671 \\
1672 \\
1673 \\
1674 \\
1675 \\
1676 \\
1677 \\
1678 \\
1679 \\
1680\end{array}$ & 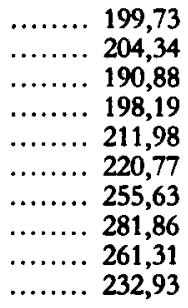 \\
\hline $\begin{array}{l}531 \\
532 \\
533 \\
534 \\
535 \\
536 \\
537 \\
538 \\
539 \\
540\end{array}$ & 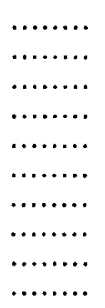 & $\begin{array}{l}34,66 \\
25,48 \\
26,81 \\
35,51 \\
28,05 \\
30,85 \\
25,93 \\
30,59 \\
31,26 \\
33,39\end{array}$ & $\begin{array}{l}1581 \\
1582 \\
1583 \\
1584 \\
1585 \\
1586 \\
1587 \\
1588 \\
1589 \\
1590\end{array}$ & $\begin{array}{l}\cdots \\
\cdots \\
\cdots\end{array}$ & $\begin{array}{l}67,11 \\
72,12 \\
81,67 \\
76,61 \\
76,46 \\
67,84 \\
74,89 \\
73,74 \\
83,44 \\
87,38\end{array}$ & $\begin{array}{l}1631 \\
1632 \\
1633 \\
1634 \\
1635 \\
1636 \\
1637 \\
1638 \\
1639 \\
1640\end{array}$ & 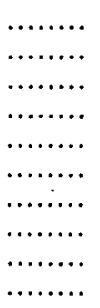 & $\begin{array}{l}142,79 \\
123,74 \\
116,80 \\
112,94 \\
111,50 \\
116,88 \\
123,50 \\
128,56 \\
119,50 \\
106,96\end{array}$ & $\begin{array}{l}1681 \\
1682 \\
1683 \\
1684 \\
1685 \\
1686 \\
1687 \\
1688 \\
1689 \\
1690\end{array}$ & $\begin{array}{cc}\ldots \ldots \ldots & 159,77 \\
\ldots \ldots \ldots . & 128,01 \\
\ldots \ldots \ldots & 170,39 \\
\ldots \ldots \ldots . & 177,18 \\
\ldots \ldots \ldots & 151,14 \\
\ldots \ldots \ldots . & 132,01 \\
\ldots \ldots \ldots . & 121,65 \\
\ldots \ldots \ldots . & 125,97 \\
\ldots \ldots \ldots . & 121,09 \\
\ldots \ldots \ldots . & 122,83\end{array}$ \\
\hline $\begin{array}{l}541 \\
542 \\
543 \\
544 \\
545 \\
546 \\
547 \\
548 \\
549 \\
550\end{array}$ & $\begin{array}{l}\ldots \ldots \ldots \\
\ldots \ldots \ldots . \\
\ldots \ldots \ldots \\
\ldots \ldots \ldots \\
\ldots \ldots . .\end{array}$ & $\begin{array}{l}29,92 \\
38,92 \\
34,53 \\
34,66 \\
31,08 \\
40,67 \\
43,37 \\
43,01 \\
54,05 \\
43,97\end{array}$ & $\begin{array}{l}1591 \\
1592 \\
1593 \\
1594 \\
1595 \\
1596 \\
1597 \\
1598 \\
1599 \\
1600\end{array}$ & ........ & $\begin{array}{r}74,95 \\
74,83 \\
75,46 \\
90,59 \\
65,59 \\
75,68 \\
73,66 \\
88,86 \\
112,56 \\
93,34\end{array}$ & $\begin{array}{l}1641 \\
1642 \\
1643 \\
1644 \\
1645 \\
1646 \\
1647 \\
1648 \\
1649 \\
1650\end{array}$ & $\begin{array}{l}\ldots \ldots \\
\ldots \ldots \\
\cdots \cdots \\
\ldots \ldots \\
\ldots \ldots \\
\cdots \cdots \\
\ldots \ldots\end{array}$ & $\begin{array}{l}136,50 \\
164,02 \\
120,89 \\
131,00 \\
137,68 \\
154,20 \\
147,80 \\
150,05 \\
151,54 \\
187,35\end{array}$ & $\begin{array}{l}1691 \\
1692 \\
1693 \\
1694 \\
1695 \\
1696 \\
1697 \\
1698 \\
1699 \\
1700\end{array}$ & 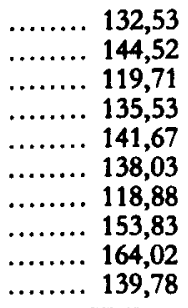 \\
\hline
\end{tabular}


Castilla la Vieja, calcular su ecuación de ajuste lineal y utilizar los coeficientes para extrapolar la serie de precios del queso de Castilla la Nueva. Puesto que una inspección de los precios del queso en ambas regiones, entre 1551 y 1700 , revela que su tendencia y fluctuaciones fueron muy similares, optamos por seguir el último de los procedimientos.

Una vez concluidos estos ejercicios procedimos a elaborar el índice ponderado de precios objeto de nuestro interés. En primer lugar asignamos las correspondientes ponderaciones a cada uno de los grupos de mercancías seleccionados, así como a cada uno de los productos integrantes de cada grupo. Los porcentajes que utilizamos son, para el periodo 1551-1700, los que aparecen en el cuadro 1, y para el período 1501-1550, los indicados en el texto. El cálculo del índice ponderado fue sencillo: el número índice que obtenemos para cada una de las series lo multiplicamos por su ponderación y el resultado lo dividimos por la suma total de las ponderaciones. El número indice final al que hemos llegado es el que se presenta en el cuadro 2, que es precisamente el nuevo índice ponderado de precios para Castilla la Nueva.

Las ponderaciones que hemos utilizado en nuestros cálculos no distan mucho de las que Phelps Brown y Hopkins emplearon para los suyos, especialmente aquellas que aplicaron en el cómputo del índice ponderado de precios para Valencia ${ }^{11}$. En nuestra decisión final tuvimos en cuenta, además, la información que sobre este tema proporciona el propio Hamilton ${ }^{12}$. Así, siguiendo su recomendación asignamos a los grupos tercero y sexto un bajo nivel de ponderación mientras que al grupo de farináceas le asignamos una ponderación alta. En 1959, cuando Phelps Brown y Hopkins reelaboraron el índice que habian construido para Inglaterra años antes, también dieron al grupo de farináceas una ponderación bastante elevada ${ }^{13}$. Por lo que se refiere a la elección de 1061-1625 como periodo base, ésta ha sido una elección arbitraria del autor, aunque se ha tratado de seleccionar un periodo medio entre 1501 y 1700 , tal y como el propio Hamilton sugirió y adoptó en sus trabajos.

11 Phelps Brown y Hopkins (1959), p. 20, y Apéndice.

12 Hamilton (1965), p. 276.

13 Phelps Brown y Hopkins (1959), p. 29. 


\section{INFLACION Y DEFLACION EN EUROPA DURANTE LOS SIGLOS XVI Y XVII: ANALISIS ESTADISTICO}

Con este nuevo índice ponderado de precios que hemos elaborado para Castilla la Nueva disponemos, por tanto, de siete índices agregados de precios de características similares ${ }^{14}$. Todos los índices son de precios corrientes, los únicos que por otra parte eran de significación para los contemporáneos ${ }^{15}, \mathrm{y}$ posiblemente proporcionan la mejor medida que en la actualidad se posee para estimar las variaciones en el coste de la vida en los siglos XVI y XVII. El propósito que perseguimos en esta sección es utilizar estos índices ponderados con objeto de llevar a cabo una medición, lo más precisa posible, de los cambios que experimentaron los precios en Europa entre 1501 y 1700 .

Antes de realizar el análisis estadístico todos los índices fueron trasladados a una base común, la media de los años 1601-25. Concluido este ejercicio procedimos a dividir cada uno de los índices en periodos de veinticinco años, comenzando en 1501. Inmediatamente después, calculamos las ecuaciones de regresión para cada número índice y para cada uno de los períodos. Inicialmente se experimentó tanto con regresiones lineales como con regresiones exponenciales, estimadas en uno y otro caso empleando el método de mínimos cuadrados. A la vista de los resultados que obtuvimos nos quedamos con las regresiones exponenciales, pues comprobamos que eran las que mejor se ajustaban a los datos. El método utilizado, aparte de su elegancia matemática, nos permite describir el crecimiento a largo plazo de cada una de estas series, teniendo presente en dicha descripción cada uno de los valores individuales.

La tasa de crecimiento que se obtiene a partir de la ecuación de ajuste es, por tanto, la tasa de crecimiento a largo plazo. No existe ningún otro procedimiento que permita el cálculo de esta magnitud cuando las series están caracterizadas, como lo están las nuestras, por variaciones anuales tan violentas. Por otro lado, el coeficiente de ajuste calculado refleja la influencia que sobre las series ejercen los factores a largo plazo, aislando aquellos que pueden ser considerados como cíclicos o coyunturales. Así, si suponemos que a largo plazo tanto la inflación como la deflación son simples fenómenos monetarios ${ }^{16}$, es decir, son el resultado del aumento o disminución de la

14 Los indices corresponden a las siguientes regiones europeas: Alsacia, Amberes, Augsburgo, Castilla la Nueva, Sur de Inglaterra, Valencia y Viena.

15 Vide, Outhwaite (1969).

16 Esta es una posición doctrinal que también comparten los keynesianos. 
cantidad de dinero, las tasas de inflación o deflación estimadas a partir de las ecuaciones de regresión, reflejarán esencialmente el aumento de precios que resulte del crecimiento de la oferta monetaria por encima del crecimiento que registre la demanda monetaria en términos reales.

Los cuadros A1 y A7 en el Apéndice resumen los resultados del ejercicio estadístico. Con objeto de facilitar el estudio comparativo que sigue, también se incluyen en el Apéndice siete gráficos que se corresponden con cada uno de los indices de precios regionales. Las tasas de crecimiento porcentuales de cada una de las series, correspondientes a cada uno de los períodos de veinticinco años, se obtuvieron directamente de las ecuaciones de regresión estimadas, y para su mejor estudio se han reunido en el cuadro 3. Los valores $R^{2}$ (coeficiente de determinación) se ofrecen en los cuadros A1- $A 7$, e indican la bondad del ajuste de cada una de las curvas de regresión. El nivel de significación se calculó de acuerdo con la tabla de posibilidades de la distribución «t». El bajo valor de $\mathrm{R}^{2}$ que se registra en algunos casos no debe ser motivo de extrañeza. Este hecho significa, o bien que la función de ajuste no era la más apropiada, o bien que la línea de regresión muestral es casi horizontal. Una observación cuidadosa de la muestra (véanse los gráficos)

\section{CUADRO 3}

Tasas de variación media anual acumulativa de los precios en diversas regiones europeas durante los siglos XVI y XVII

(en porcentajes)

\begin{tabular}{|c|c|c|c|c|c|c|c|c|}
\hline & $\begin{array}{c}1501- \\
1525\end{array}$ & $\begin{array}{r}1526 \\
1550\end{array}$ & $\begin{array}{c}1551 \\
1575\end{array}$ & $\begin{array}{c}1576- \\
1600\end{array}$ & $\begin{array}{c}1601 \\
1625\end{array}$ & $\begin{array}{c}1626 \\
1650\end{array}$ & $\begin{array}{l}1651- \\
1675\end{array}$ & $\begin{array}{l}1676 \\
1700\end{array}$ \\
\hline Alsacia & 0,872 & 1,300 & 2,803 & 2,190 & 2,640 & $-0,124$ & 0,153 & 0,136 \\
\hline Amberes $\ldots \ldots \ldots \ldots$..... & 1,904 & 0,855 & 1,972 & 1,117 & 1,117 & 0,571 & $-0,625$ & 1,103 \\
\hline Augsburgo $\ldots \ldots \ldots .$. & $-0,245$ & 0,886 & 2,686 & 1,365 & 3,178 & $-0,163$ & $-0,327$ & 1,665 \\
\hline Castilla la Nueva" & 0,794 & 2,276 & 2,101 & 1,102 & 0,915 & 1,084 & 1,617 & $-2,408$ \\
\hline Castilla la Nueva ${ }^{b}$... & 0,728 & 1,360 & 1,910 & 1,181 & 0,409 & 0,373 & 1,022 & $-1,834$ \\
\hline Sur de Inglaterra & 1,379 & 1,710 & 0,224 & 2,123 & 0,647 & 1,168 & $-0,053$ & 0,555 \\
\hline Valencia .............. & 0,475 & 0,837 & 1,528 & 1,175 & $-0,150$ & 0,352 & $\cdots$ & $\cdots$ \\
\hline Viena $\ldots \ldots \ldots \ldots \ldots$ & 0,420 & 1,094 & 2,224 & 2,355 & 4,026 & 0,613 & $-0,189$ & 2,890 \\
\hline
\end{tabular}

NotAs:

... No disponible

- Calculado a partir del índice de precios ponderado.

- Calculado a partir del indice de precios simples de Hamilton.

Fuentes: Apéndice A. 
sugiere que, en la mayoría de los casos, la última de las interpretaciones es probablemente la más acertada. Esto es, cuando el valor $\mathbf{R}^{2}$ es bajo significa que en comparación con la influencia que pudieran ejercer otras causas, los factores seculares proporcionaron una influencia débil en la evolución general de los precios. $\mathrm{El}$ análisis que hemos realizado dividiendo los doscientos años en períodos de veinticinco años tiene precisamente la virtud de aislar aquellos períodos en los que las perturbaciones aleatorias ejercieron una influencia más significativa que los factores seculares.

Analicemos ahora los datos reunidos en el cuadro 3 y en el Apéndice. Dos son las notas más destacadas que se desprenden de la observación de las cifras. Por un lado confirmamos la concordancia que se produjo en la evolución de los precios europeos, particularmente entre 1501 y 1625 . El cuadro 3 pone de relieve que el alza de los precios fue un fenómeno general y que las discrepancias registradas en el ritmo de variación de las diferentes regiones fueron mínimas ${ }^{17}$. Por lo que se refiere al crecimiento anual de los indices, constatamos lo moderado de las tasas de inflación que caracterizó la llamada «revolución de los precios». En general las tasas más altas se registraron durante la segunda mitad del siglo XVI y el primer cuarto del siglo XVII, aunque sólo en dos ocasiones fueron superiores al 3 por ciento. La inflación media europea pudo situarse, de acuerdo con nuestras estimaciones, en torno al 2 por ciento medio anual entre 1551 y 1575 , y alrededor de 1,5 por ciento anual de 1576 a 1625 . Antes y después, el crecimiento de los precios estuvo por debajo de este porcentaje. Asi, si algún periodo merece ser distinguido con el nombre de "revolución de los precios», éste sería sin duda el comprendido entre 1550 y 1625. A la vista de estos datos creo que está plenamente justificado hablar de un siglo XVI «largo», como hacen Braudel y Spooner, puesto que la subida de los precios no se interrumpe en 1600 , sino que se prolonga de forma generalizada hasta bien entrado el siglo XVII ${ }^{18}$.

La moderada inflación que claramente revela nuestro análisis estadistico no es, sin embargo, algo que se descubre aquí por primera vez. Carlo $M$. Cipolla ya tuvo ocasión de restar dramatismo al término «revolución de los precios» cuando llamó la atención sobre el hecho de que entre 1552 y 1600 , la tasa de crecimiento de los precios italianos apenas fue superior al 2 por ciento medio anual ${ }^{19}$. Ahora bien, llegados a este punto quizá convenga hacer una

17 Esta conclusión no es, por supuesto, novedosa, sino que ha sido destacada con anterioridad por distintos autores; véanse, por ejemplo, los trabajos de Braudel y Spooner (1967), passim; Wallerstein (1974), p. 70 et seg.

18 Braudel y Spooner (1967).

19 Cipolla (1972), p. 44. 
puntualización; aunque ciertamente las tasas de crecimiento que hemos calculado son muy moderadas y pueda, por tanto, parecer un exceso verbal calificar el alza del siglo XVI como revolucionario, es preciso tener en cuenta dos argumentos a favor del valor y eficacia del término. Primero, para los contemporáneos un aumento de los precios en torno al 2 por ciento fue verdaderamente revolucionario, a pesar de que no lo sea para nosotros, acostumbrados a una inflación de dos dígitos. Hemos de recordar, además, que el aumento de los precios estuvo precedido de un largo período de deflación y estabilidad. Lo que esenciàlmente da el carácter revolucionario a la subida del siglo XVI es su persistencia a lo largo de casi un siglo y medio. Este fue el fenómeno que posiblemente más llamó la atención de los observadores contemporáneos y al que trataron de buscar una explicación ${ }^{20}$. Su duración fue lo que provocó, por otra parte, el que hacia 1625 los precios se hubiesen multiplicado por cinco con respecto a 1500 .

Por lo que se refiere al período del siglo XVII comprendido entre 1626 y 1700 , la evolución de los precios europeos no parece que mostrase tanta uniformidad como en el periodo anterior. De 1626 a 1650 la inflación remitió en la mayoría de las áreas que abarca nuestro estudio, excepto en Inglaterra y en las dos regiones españolas. Alsacia y Augsburgo, por su parte, registran deflación. De 1651 a 1675 , la deflación se generaliza, con la salvedad de Castilla la Nueva y Alsacia. Finalmente, y de modo contrario a la tendencia europea, los precios castellanos registraron una persistente caída en el último cuarto de siglo.

El cuadro 3 muestra, además, que el indice de Castilla la Nueva, uno de los centros hamiltonianos de la revolución de los precios del siglo XVI ${ }^{21}$, no experimentó una tasa de crecimiento superior a la registrada en el resto de Europa. Nuestros cálculos confirman, por tanto, la opinión de Georg Wiebe, quien en 1895 sostuvo que el aumento de los precios en Alemania y Francia había sido más pronunciado que en España 22. Para entender esto se ha de recordar que Hamilton hizo sus comparaciones no con los precios corrientes, sino en términos de precios plata, lo cual le llevaba a ocultar la inflación que se producía a consecuencia de la depreciación de la moneda ${ }^{23}$, fenómeno que fue muy intenso en la Europa del siglo XVI ${ }^{24}$, aunque no lo fuese en Castilla durante los reinados de Carlos. I y Felipe II. La estabilidad de la moneda

20 Vide, Mauro (1970); Van der Wee y Peeters (1970).

21 Hamilton (1965), pp. 205-10.

22 Wiebe (1895), citado por Hamilton (1965), p. 207, n. 1.

23 El propio Hamilton $(1965$, p. 207, n. 1) reconoció este punto.

24 Braudel y Spooner (1967), p. 458; Gould (1970), passim. 
castellana quebró con la llegada del tercero de los Austrias y fue precisamente a partir de entonces, y por dicho motivo, cuando los precios en Castilla la Nueva siguieron una pauta diferente de la de los precios europeos. Existe otra razón por la cual los precios castellanos no tenían por qué subir necesariamente más que en el resto del continente, a pesar de ser la primera región receptora del Tesoro americano. Sabemos, por ejemplo, que no toda la plata que llegaba a Sevilla acudía a las cecas españolas, sino que era exportada directamente ${ }^{25}$. Además, tenemos evidencia, tanto para el siglo XVI como para la primera década del siglo XVII, de que a pesar de la abundancia de las llegadas del metal, existió escasez de dinero ${ }^{26}$, y que ni siquiera el desarrollo de otros medios de pago fue suficiente para satisfacer adecuadamente las necesidades de caja de las ferias castellanas ${ }^{27}$.

\section{PRECIOS Y CANTIDAD DE DINERO}

Nuestro ejercicio estadístico también nos permite adentrarnos en el debatido tema de las causas por las cuales subieron los precios. Como es bien sabido, Hamilton en sus trabajos defendió una interpretación monetarista pura, muy similar a la que ofrecieron los bullonistas españoles del siglo XVI ${ }^{28}$. El ascenso del keynesianismo en las décadas que siguieron a la segunda guerra mundial sustituyó la explicación monetarista por otra basada en factores demográficos ${ }^{29}$. Empero, la mayoría de las objeciones que los historiadores económicos keynesianos hicieron a la interpretación de los monetaristas han sido ya replicadas.

Diversos autores han señalado, por ejemplo, que un aumento de la población si no va acompañado de un aumento en la cantidad de dinero tiene efectos deflacionistas, por lo que la expansión demográfica por sí sola no pudo haber sido la causa del crecimiento de los precios ${ }^{30}$. Estos mismos

25 Véase Phillips y Phillips (1977), pp. 413-430, y Ullon (1975), pp. 459-479.

26 Vide, Carande (1965), p. 227, 248 y pp. 337-40, y Taylor (1968), passim. También, Flynn (1978).

27 Vide, Ramón Carande (1965) pp. 337-40, y Vicens Vives, (1965), pp. 340-42.

28 Sobre el debate y la postura de los bullonistas, véase, por ejemplo, el resumen que ofrece Outhwaite (1969).

$29 \mathrm{La}$ interpretación monetaria ha sido atacada en un conjunto de trabajos editados por Ramsey (1971). Entre nosotros la explicación monetarista ha sido puesta en duda por J. Nadal (1959), pp. 503-29.

30 De hecho, un aumento de la población sin que paralelamente se produzca un incremento de la cantidad de dinero tiene efectos deflacionistas sobre el nivel de precios. Véase McCloskey 
autores mantienen que la teoría cuantitativa tan sólo trata de proporcionar una explicación de las variaciones del nivel absoluto de precios, y que las diferencias que se observan en el ritmo de crecimiento de los precios de los productos agrarios vis à vis el precio de los productos no agrarios, reflejan variaciones en los precios relativos, por lo que no desacreditan en lo más mínimo la interpretación monetarista. Cambios en los precios relativos suelen ser el producto de cambios en el tamaño de la población y en la productividad de los factores, y confundir sus variaciones con aquellas que se producen en los precios absolutos supone incurrir en un grave error teórico. Por su parte, Harry Miskimin sostiene que la falta de correspondencia que se observa en algunos casos entre las importaciones de plata y la evolución de los precios, tampoco desautoriza la tesis de Hamilton y de los monetaristas ${ }^{31}$. En primer lugar, se ha de tener presente que el aumento de los precios en el primer tercio del siglo XVI reflejó no sólo las llegadas de metal americano, sino también el notable aumento de la producción de plata de las minas europeas. Por otra parte, el argumento de la falta de correspondencia entre incrementos de precios e incrementos en las importaciones de metales preciosos está basado en el supuesto de que la demanda de dinero permaneció invariable. Ahora bien, puesto que parece razonable pensar que el aumento del volumen en las necesidades financieras de los Estados afectasen la cantidad de dinero demandada, la tasa de inflación a largo plazo reflejaría no sólo el incremento en la oferta de metales, sino también el aumento de la demanda de saldos reales ${ }^{32}$.

En el caso de España sabemos que en la primera mitad del siglo XVI las importaciones totales de metal fueron poco importantes, y que sólo a partir de 1551 parecen haberse incrementado sustancialmente. De hecho, entre este último año y 1575, la cantidad de oro y plata importada y registrada en la Casa de Contratación fue tres veces superior a la registrada en los veinticinco años anteriores. De acuerdo con la teoría cuantitativa, los precios deberían haber acelerado su crecimiento a partir de 1551, y, según muestra el cuadro 3, eso fue precisamente lo que ocurrió. Es cierto, sin embargo, que la tasa de inflación en el último cuarto de siglo se desacelera, mientras las importaciones de plata siguen aumentando. Esta falta de concordia no invalida, a mi entender, la explicación hamiltoniana. Las referencias que se tienen sobre

(1972), pp. 1332-35; Gadiel y Falkus (1969), pp. 9-16; Flynn (1978), p. 389. La última defensa de la interpretación monetarista la ha realizado Fisher (1989), pp. 884-902, y la contraofensiva la ha llevado a cabo Goldstone (1991), pp. 176-181.

31 H. A. Miskimin (1977), pp. 38-40.

32 Flynn (1978), passim. 
"escasez" de numerario en los últimos decenios del siglo XVI dan pie a pensar que posiblemente al finalizar la centuria la demanda de dinero, por diveros motivos, crecía a un ritmo mayor que la oferta monetaria. Si esto es cierto, lo lógico era esperar que la inflación remitiese, y eso fue, según muestran nuestras estimaciones, lo que sucedió.

Volviendo a la información que proporciona el cuadro 3 sobre las tasas de inflación del siglo XVI, la pregunta que a mi modo de ver debemos hacernos no es tanto "¿por qué subieron los precios?", sino "¿por qué subieron tan moderadamente?». La respuesta a esta pregunta se ha de buscar no en aquellas causas que tradicionalmente se ofrecen para explicar la inflación, sino que debemos fijarnos más en los factores que pudieron ejercer presiones deflacionistas al tiempo que se producía la avalancha de metales preciosos. En la próximas páginas examinamos dos de estos factores.

El primero que ha de tomarse en consideración es el déficit persistente de la balanza de pagos de Europa Occidental con el Báltico y con el Lejano Oriente. Miskimin ha señalado el carácter de «hard currency» que tenían estas dos regiones y que exigian, por tanto, que Europa Occidental liquidase sus saldos comerciales negativos en oro y plata ${ }^{33}$. De este modo cabe suponer que una gran parte del stock de metales europeos frese aminorado para satisfacer estos déficit. Las políticas mercantilistas adoptadas por los diversos Estados nacionales y las leyes aprobadas con objeto de prohibir las exportaciones de efectivo sugieren que la reducción del stock metálico se producía a ritmos alarmantes. El impacto de esta disminución constante de la reserva de oro y de plata tuvo que ser necesariamente deflacionista, y sin duda sirvió para establecer un techo más allá del cual los precios no podían aumentar.

Para explicar el segundo factor se han de considerar las relaciones entre los incrementos de la cantidad de dinero, los aumentos de la población y las variaciones de la demanda de dinero en términos reales ${ }^{34}$. Con objeto de llegar a una comprensión más fácil de estas relaciones hacemos uso del modelo de análisis macroeconómico IS-LM.

Comenzamos por suponer que estamos en una posición de equilibrio tal y como la que señala el punto $\mathrm{E}_{1}$ del gráfico ${ }^{35}$. Examinemos cuál es el efecto

${ }^{33}$ Miskimin (1977), p. 149, y de la misma opinión, Parker (1974), pp. 527-30. Sobre los "destinos» de la plata americana, véase el reciente estudio de Ruiz Martín (1990a).

34 Para un análisis similar, véanse Flynn (1978) y Fisher (1989). Entre nosotros, Ruiz Martin (1973) fue el primero en llamar la atención sobre la necesidad de considerar la demanda y la oferta monetarias de forma conjunta.

${ }^{35}$ Podemos suponer que las condiciones de equilibrio representadas por el punto $E$ eran las que caracterizaban a las distintas economías europeas de mediados del siglo Xvi. Esto es, la curva 


\section{GRAFICO 1}

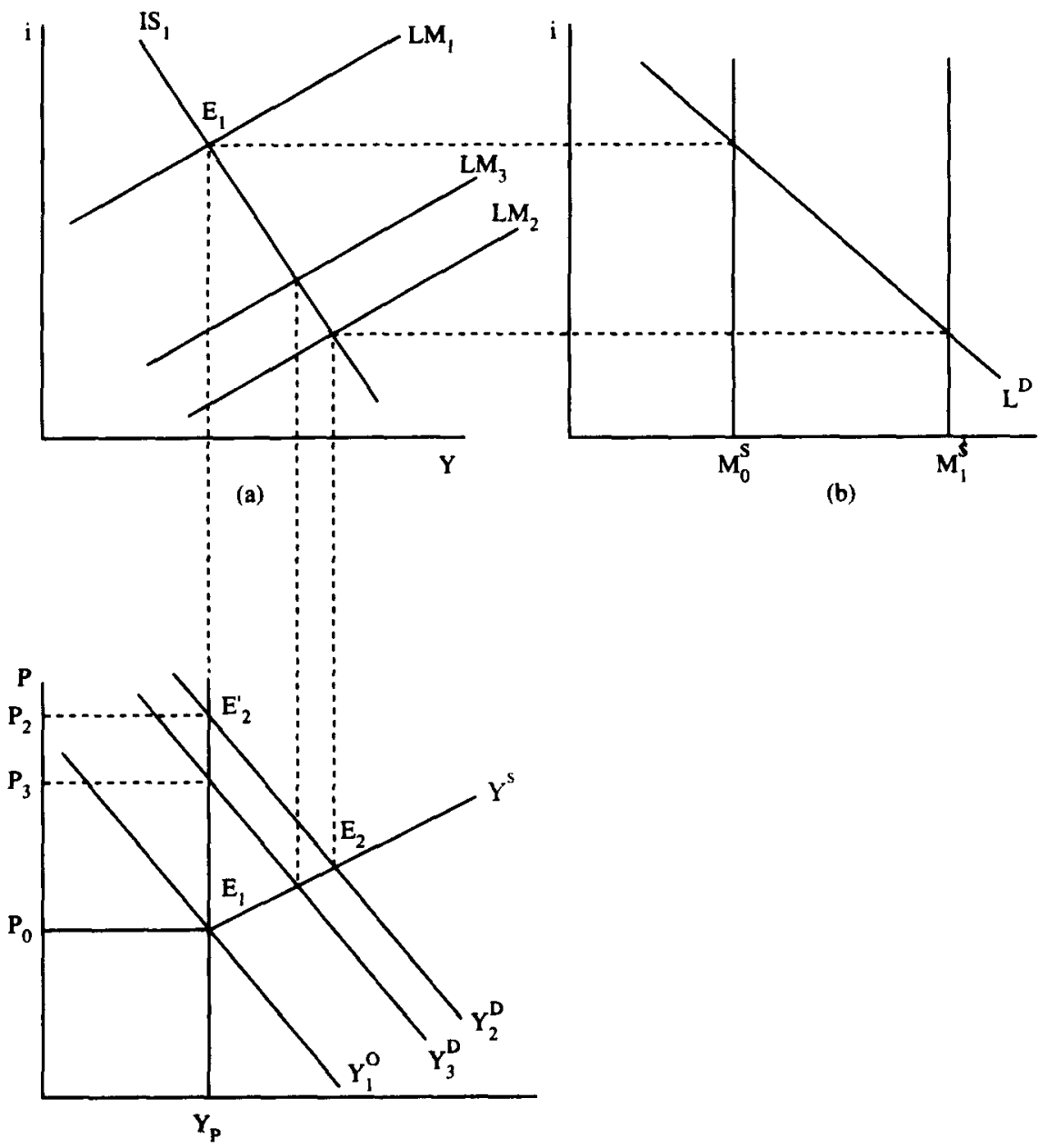

(c)

sobre el nivel de precios de un aumento de la oferta monetaria $\left(M^{5}\right)^{36}$. Como consecuencia del aumento de la cantidad de dinero (de $M_{0}^{s}$ a $M_{1}^{s}$ ) la curva LM

de demanda agregada de la economia había alcanzado la parte ascendente de la curva de oferta a corto plazo (zona de costes marginales crecientes). Véase Mauro (1970), p. 218, y Van der Wee y Peeters (1970), p. 100 et seq.

${ }^{36}$ El análisis y los resultados son los mismos si en lugar de comenzar con una alteración monetaria comenzamos con un cambio real; por ejemplo, con un aumento del gasto autónomo debido a un incremento de población. 
experimenta un desplazamiento hacia la derecha (de $\mathrm{LM}_{1}$ a $\mathrm{LM}_{2}$ ), lo que determina que la curva de demanda agregada $Y_{1}^{D}$ también experimente un desplazamiento hacia $Y_{2}^{D}$. A corto plazo y al nivel de precios inicial $P_{0}$, hará su aparición un exceso de demanda. Esto último estimulará, a su vez, una expansión del volumen de producción y también probablemente un aumento en el nivel de precios ${ }^{37}$. En el nuevo punto de equilibrio $E_{2}$, el output corriente excede al nivel de producción potencial o de pleno empleo de los recursos. A menos que la economía experimente un aumento en el volumen de recursos disponibles o se registre un incremento en la productividad de los factores, el punto $\mathrm{E}_{2}$ es sólo un punto de equilibrio temporal. A largo plazo, el incremento en el coste de los factores hará que la curva de demanda agregada se desplace hacia arriba y ello irá acompañado de un aumento en el nivel de precios. Este aumento disminuirá el volumen total de saldos monetarios en términos reales a disposición de la economía, lo que hará que aumenten los tipos de interés y, en última instancia, se reduzca la demanda agregada. En $E_{2}^{1}$, la economía alcanza su punto final de equilibrio.

En toda esta descripción, la macromagnitud que ha quedado relegada a un segundo plano es la demanda de dinero. Es evidente, sin embargo, que el incremento en el nivel de renta ha traido consigo un aumento de la demanda de dinero, y ha servido además para establecer un límite superior a los incrementos que pudieran producirse en el nivel de precios. En nuestro gráfico, el aumento de la demanda de dinero derivado del aumento del output está ya incorporado en la naturaleza de la curva LM, cuya pendiente es positiva. Empero, existe un aumento del volumen de saldos reales demandados por las unidades económicas diferente del que se genera a consecuencia del incremento del nivel de renta, y que va a originar que la curva LM se desplace hacia la izquierda, hasta $\mathrm{LM}_{3}$. Este aumento de la demanda de dinero está asociado a lo que en la literatura económica se conoce como «efecto riqueza». Para entender su importancia y poder incorporarlo a nuestro análisis es preciso definir una demanda de dinero que no sea únicamente función de la renta corriente del período, sino que entre sus argumentos estén todas las fuentes posibles de ingreso ${ }^{38}$. Tal función deberia incluir al menos cuatro de

37 La división entre precios y output es un punto crucial en la literatura económica. Véase, por ejemplo, Friedman (1970), pp. 193-238. En nuestro caso, dadas las rigideces institucionales y los limites impuestos por la tecnologia renacentista, lo más probable es que la división viniera determinada por las condiciones de oferta, esto es, por las elasticidades de la curva de oferta a corto plazo. Cuanto menos elástica fuese dicha curva, mayor sería el aumento de los precios y menor el incremento de la producción.

38 Véase Friedman (1956), pp. 3-21. 
las varias formas en que una economía puede mantener riqueza: dinero, deuda pública y privadas; capital y bienes fisicos, y capital humano. Un incremento en cualquiera de estos componentes determina un aumento de la demanda de dinero, lo cual se traduce, en nuestro modelo, en un desplazamiento hacia la izquierda de la curva LM. Lo que el análisis tradicional sobre la revolución de los precios del siglo XVI ha relegado es precisamente el efecto autónomo que se produjo en la cantidad de dinero demandada, como consecuencia del incremento en capital humano y en activos financieros registrado entre 1500 y 1600.

Con objeto de comprender lo primero, el incremento del capital humano, es necesario considerar el aumento de la población no sólo por el lado del consumo, es decir, como una fuente de demanda de nuevos bienes y servicios, sino también por el lado de la oferta, es decir, como incremento neto al volumen total de bienes de capital intermedio disponibles. Por lo que se refiere al incremento de los activos financieros de la comunidad económica del siglo XVI, sabemos que fue el resultado directo del aumento de la deuda pública, ya que si algún acontecimiento caracterizaba la vida financiera del siglo XVI era precisamente el creciente endeudamiento de las Coronas europeas y demás instituciones públicas ${ }^{39}$.

Si se aceptan nuestros argumentos, parece necesario, por tanto, tener en cuenta el aumento paralelo experimentado por los saldos reales demandados como consecuencia del «efecto riqueza», al analizar el impacto que tuvo la llegada del Tesoro americano sobre los precios europeos. El gráfico muestra que en la posición final de la curva $\mathrm{LM}$, en $\mathrm{LM}_{3}$, el nivel de precios de equilibrio final $\mathrm{P}_{3}$ está por debajo de $\mathrm{P}_{2}$, punto que se hubiese alcanzado de no haber existido un incremento adicional de la demanda de dinero. La inflación en lugar de ser $\mathrm{P}_{0} \mathrm{P}_{2}$ ha quedado reducida a $\mathrm{P}_{0} \mathrm{P}_{3}$.

\section{RELACIONES DE CAMBIO INTERSECTORIAL}

En las secciones anteriores nuestro estudio se ha centrado en la evolución de los precios absolutos en siete regiones europeas. En esta parte pasamos a ocuparnos del comportamiento de los precios relativos. Nuestro objetivo es analizar y comparar las relaciones de cambio intersectorial de cuatro regiones

39 Véase Miskimin (1977), pp. 155-82; también, Ruiz Martín (1968), pp. 109-173, y Ruiz Martín (1990b), passim. 
(Alsacia, Brabante, Inglaterra y Castilla la Nueva), que pueden considerarse representativas de tipos diferentes de economía.

Es bien sabido que en el siglo XVI los precios de los productos agrarios aumentaron en una proporción mayor que los precios de las manufacturas. Obviamente, las diferencias variaron de una región a otra, dependiendo de las peculiaridades económicas de cada una de ellas. Cabe afirmar, sin embargo, que la razón por la cual el comportamiento de los precios de los bienes primarios y de los productos manufacturados fue distinto es en todos los casos la misma. Las variaciones de los precios relativos reflejaron, esencialmente, la existencia de elasticidades (renta y precio) de oferta y demanda de bienes intermedios y finales diferentes en cada uno de los sectores. En otras palabras, la respuesta del sector agrario y del sector manufacturero al aumento de la población varió dependiendo de las características técnicas de la producción en cada uno de los dos sectores y de las peculiaridades de las funciones de demanda correspondientes. En general, el aumento de la producción agraria se produjo sin transformaciones tecnológicas; en terminología económica diríamos que se produjo sin cambios en la función de producción ${ }^{40}$, mientras que el sector manufacturero experimentó notables cambios en la productividad de los factores ${ }^{41}$. Peter Bowden ha sugerido, además, que las variaciones registradas en el nivel y distribución de la renta en el siglo XVI trajeron consigo cambios notables en las pautas de consumo de la población, alterándose la proporción del gasto que los individuos destinaban a cada uno de los bienes, lo cual influía a su vez en la estructura de precios $^{42}$.

Para estudiar las relaciones de cambio intersectorial ha sido preciso construir los correspondientes números índices. Como representativo del indice general de precios de los productos agrarios, se ha tomado un índice de precios compuesto a partir de los precios de mercado de los principales granos. El índice de precios representativos de los productos manufacturados

40 Podria argumentarse que en algunas áreas de Europa, particularmente en los Países Bajos e Inglaterra, se produjeron ganancias de productividad, lo que habria desplazado la curva de oferta hacia la derecha. Véase, por ejemplo, Slicher van Bath (1963), y Davis (1973). Para los Paises Bajos, puede consultarse Slicher van Bath (1960), pp. 130-53. Para Inglaterra, Thirsk (1967), pp. 161-199, y Bowden (1967), Pp. 593-695.

41 Por supuesto el argumento no sería de aplicación a las regiones mediterráneas, pero sí al caso de Inglaterra. Véanse, por ejemplo, los trabajos de Nef (1965a y 1965b), pp. 240-67 y pp. 144-212.

42 Bowden (1967a), p. 601. En términos de la ecuación de Slutsky significa que un elevado número de bienes son *bienes inferiores", y que el efecto renta que se produce al disminuir los ingresos fue lo suficientemente fuerte para compensar el signo negativo del efecto sustitución. 


\section{CUADRO 4}

Relaciones de cambio intersectoriales, 1551-1640

(Números indice)

\begin{tabular}{|c|c|c|c|c|c|c|c|c|}
\hline \multirow[b]{2}{*}{ Periodo } & \multicolumn{2}{|c|}{ Alsacia ${ }^{*}$} & \multicolumn{2}{|c|}{ Brabante $^{b}$} & \multicolumn{2}{|c|}{ Castilla la Nuevac } & \multicolumn{2}{|c|}{ Inglaterra ${ }^{\mathrm{d}}$} \\
\hline & Indice & $\begin{array}{c}\text { Variación } \\
\%\end{array}$ & Indice & $\begin{array}{c}\text { Variación } \\
\%\end{array}$ & Indice & $\begin{array}{c}\text { Variación } \\
\%\end{array}$ & Indice & $\begin{array}{c}\text { Variación } \\
\%\end{array}$ \\
\hline $1551-60 \ldots \ldots \ldots \ldots \ldots$ & 158,0 & & 101,4 & & 71,1 & & 85,6 & \\
\hline $1561-70 \ldots \ldots \ldots \ldots \ldots$ & 179,0 & 13,3 & 91,6 & $-9,7$ & 77,2 & 8,6 & 67,7 & $-20,5$ \\
\hline $1571-80$ & 205,0 & 14,5 & 100,8 & 10,0 & 71,7 & $-7,1$ & 79,9 & 18,0 \\
\hline $1581-90 \ldots \ldots$. & 222,0 & 8,3 & 123,9 & 22,9 & 82,1 & 14,5 & 91,4 & 14,4 \\
\hline $1591-1600 \ldots \ldots \ldots \ldots$ & 219,0 & $-1,4$ & 100,0 & $-19,3$ & 84,4 & 2,8 & 104,3 & 14,1 \\
\hline $1601-10 \ldots \ldots \ldots \ldots \ldots$ & 182,0 & $-16,9$ & 113,3 & $\ldots$ & 96,9 & 14,8 & 91,1 & $-12,7$ \\
\hline $1611-20 \ldots \ldots \ldots \ldots \ldots$ & 171,0 & $-6,0$ & 100,3 & $-11,5$ & 101,7 & 5,0 & 102,3 & 12,3 \\
\hline $1621-30 \ldots \ldots \ldots \ldots \ldots$ & 249,0 & 45,6 & 123,6 & 23,2 & 102,8 & 1,1 & 109,3 & 6,8 \\
\hline $1631-40 \ldots \ldots \ldots \ldots \ldots$ & 336,0 & 34,9 & 126,3 & 2,2 & 86,6 & $-15,8$ & 108,1 & $-1,1$ \\
\hline \multicolumn{9}{|l|}{ Variación } \\
\hline $1551-60 / 1631-40 \ldots \ldots$ & & 112,7 & & $\ldots$ & & $44,6^{\circ}$ & & 26,3 \\
\hline $1551-60 / 1591-1600 \ldots$ & & 38,6 & & $-1,4$ & & 18,7 & & 22,4 \\
\hline $1601-10 / 1631-40 \ldots \ldots$ & & 84,6 & & 11,5 & & $-10,6$ & & 18,7 \\
\hline
\end{tabular}

NotAs:

- Para Alsacia, véase explicación en el texto.

b De 1551 a 1600, Base $1551-60=100$; de 1601 a 1640 , Base $1601-10=100$.

c Base 1601-25=100.

d Base $1601-25=100$.

- Variación porcentual correspondiente al período 1551-60/1621-30.

Fuente: Apéndice B.

se ha elaborado a partir de una pequeña muestra con los precios de las principales mercancías no agrarias para las cuales se dispone de información.

Afortunadamente para Castilla la Nueva e Inglaterra ha sido posible emplear los indices de precios de granos que proporcionan los trabajos de Hamilton y Bowden, respectivamente ${ }^{43}$. Los indices son homogéneos y la única transformación ha sido su reducción a una base común (1601$25=100$ ). La elaboración del indice de precios de manufacturas para Castilla la Nueva ha sido algo más laboriosa y su composición se expone en el Apéndice B. En el caso de Inglaterra tal indice no ha presentado mayor

43 Hamilton (1965), pp. 390 y ss.; Bowden (1967b), pp. 814-870. 
problema, pues hemos tomado el índice de precios industriales que ha elaborado R. Doughty ${ }^{44}$. Para Brabante los números índices correspondientes se han construido a partir de los datos publicados por Herman Van der Wee ${ }^{45}$, y su composición también se expone en el Apéndice. Finalmente, para analizar las relaciones de intercambio en Alsacia nos hemos limitado a hacer uso de los índices desagregados que presentan Phelps Brown y Hopkins ${ }^{46}$. Todos los índices y relaciones de cambio intersectorial han sido calculados anualmente, excepto para Alsacia, y se ofrecen en el Apéndice B. Por su parte, el cuadro 4 resume la información y muestra la evolución de las relaciones de cambio intersectorial en medias decenales.

Como puede comprobarse, los resultados que se presentan confirman la hipótesis más generalmente aceptada de que las relaciones de cambio intersectoriales fueron favorables al sector agrario. Lógicamente esto significa que en el periodo comprendido entre 1551 y 1640 se produjo una transferencia neta de renta hacia la agricultura. Los porcentajes de variación que observamos sugieren que la magnitud de esta transferencia difiere de un área a otra, y que aparentemente fue más intensa en regiones de economía más atrasada (Alsacia y Castilla la Nueva) que en regiones con una economía más diversificada (Bravante e Inglaterra).

A largo plazo se produjo, por tanto, una transferencia de recursos hacia la agricultura, especialmente durante el siglo XVI, lo cual significó un incremento de la capacidad de gasto del sector. El efecto último que esta transferencia ejerció sobre la producción agraria y sobre las manufacturas locales es dificil de precisar, pero en todo caso tuvo que depender de la estructura social, esto es, de qué grupos sociales recibieron los beneficios del aumento de los precios, así como de la mayor o menor movilidad de los factores productivos. En Inglaterra, donde las ganancias no fueron capturadas exclusivamente por los «señores", sino que parte parecen haber sido recibidas por una nueva clase de propietarios (the gentry) y por labradores acomodados, cuyos derechos sobre la tierra estaban establecidos desde siglos anteriores, la transferencia de renta del sector urbano al rural tendió a crear un amplio mercado para las manufacturas locales y permitió una tasa de ahorro e inversión mayor. El progreso de la agricultura y de la manufactura inglesa en los siglos XVI y XVII así lo atestigua. Por el contrario, en otras regiones europeas en las cuales la tendencia de los precios relativos fue similar no se registró un desarrollo

4 Doughty (1975), pp. 188-191; en medias decenales también podemos utilizar los índices utilizados por Phelps Brown y Hopkins y el de Bowden.

45 Var der Wee (1978), pp. 169-326, y Van der Wee (1975), pp. 436-447.

46 Phelps Brown y Hopkins (1957), pp. 306. 
paralelo de su economia, en parte porque, dada la estructura de propiedad, el reparto de los beneficios tuvo que ser muy desigual. Nuestros cálculos también revelan otro rasgo importante. Observamos que las ganancias a largo plazo del sector rural no se manifiestan tan claramente si contemplamos los datos anuales o por periodos decenales. Asi, el cuadro 4 pone de relieve que hubo determinadas décadas en las cuales las relaciones de cambio intersectorial se inclinaron a favor del sector manufacturero.

Otro rasgo que merece ser destacado es la existencia de notables diferencias en el comportamiento de las relaciones de cambio en cada una de las regiones. Mientras los precios relativos, entre 1551-1600, evolucionaron de modo favorable al sector agrario en Alsacia, Inglaterra y Castilla la Nueva, en Brabante lo hicieron a favor de las manufacturas. En el periodo siguiente, 1601-40, las diferencias también son destacables. En Alsacia, Brabante e Inglaterra, el comportamiento de los precios favoreció al sector agrario, mientras que en Castilla la Nueva favorecieron a la agricultura hasta 1630 y a partir de entonces se inclinaron en favor del sector manufacturero. Obviamente, estas diferencias de los precios relativos a medio y corto plazo sugiere que las condiciones de oferta y demanda sectoriales eran diferentes en cada una de las regiones que estamos analizando. Estos resultados confirman, por otra parte, ideas avanzadas por Van der Wee acerca de la existencia de estructuras económicas diferentes en la Europa preindustrial de los siglos XVI y XVII ${ }^{47}$.

Por último, también debemos resaltar que una inspección cuidadosa del Apéndice muestra que, a corto plazo, las relaciones de cambio intersectoriales registraron violentas fluctuaciones anuales, cuya influencia macroeconómica es preciso tener en consideración. Podría argüirse, por ejemplo, que las oscilaciones que observamos en las relaciones de cambio intersectorial introdujeron notables dosis de incertidumbre, tanto en el sector rural como en el sector urbano, que afectó al nivel y evolución de la «renta permanente» de los distintos agentes económicos. Esta incertidumbre, lejos de ser totalmente perjudicial, posiblemente fomentó un volumen de ahorro mayor que si las relaciones de cambio hubiesen seguido una senda más estable. Si esto fuese cierto, cabría sugerir que las fluctuaciones en los términos de intercambio favorecieron la acumulación de capital, lo cual a su vez permitió una tasa de inversión más elevada en las décadas siguientes y, por consiguiente, un ritmo de crecimiento mayor.

47 Van der Wee (1978), p. 67 et seq. 


\section{CONCLUSIONES}

El objetivo principal de este trabajo ha sido proporcionar una medición lo más precisa posible del crecimiento de los precios en Europa entre 1500 y 1700. En la sección II calculamos para Castilla la Nueva un índice ponderado de precios que fuese homogéneo con el de otras regiones europeas, y así poder incorporar a nuestro estudio una de las áreas en las que tradicionalmente se ha centrado el examen de la revoluciớn de los precios. En la sección III hemos estimado las tasas de inflación para períodos de veinticinco años en siete regiones europeas y hemos confirmado que el crecimiento o decrecimiento de los precios fue, en todos los casos, muy moderado. A continuación, y empleando los instrumentos que suministra la moderna teoría monetaria, hemos tratado de ofrecer una interpretación del comportamiento de los precios durante el siglo XVI. A mi entender, la teoría cuantitativa del dinero sigue proporcionando la mejor explicación de los cambios a largo plazo en el nivel absoluto de precios, aunque es preciso advertir que la nueva interpretación monetarista se fundamenta no en términos de la tautonómica ecuación de Fisher, sino en las recientes formulaciones de la teoría cuantitativa. Añadamos, por último, que a pesar del fuerte significado que tiene el concepto «revolución de los precios" parece conveniente que conservemos el término. De un lado, respetamos la visión que tenían los contemporáneos del fenómeno, y, de otro, reconocemos el hecho de que aunque las tasas de inflación del siglo XVI no fueron excepcionalmente altas, el aumento de los precios se mantuvo durante más de diez décadas consecutivas. Finalmente, en la última sección hemos examinado las relaciones de cambio intersectorial para cuatro regiones europeas; la principal conclusión es que se produjo una transferencia de recurso del sector urbano al rural, que tuvo importantes efectos mactoeconómicos. 


\section{APENDICE A. Análisis de regresión de los índices ponderados} de precios de consumo en varias regiones europeas

\section{CUADRO A-1}

Alsacia: Análisis de Regresión del Indice Ponderado de Precios de Consumo, 1501-1700

Base, media $1601-25=100$

$$
\mathrm{Y}=\mathrm{a} \cdot \mathrm{b}^{\mathbf{x}}
$$

\begin{tabular}{|c|c|c|c|c|c|c|c|}
\hline Años & Media & $\begin{array}{l}\text { Desviación } \\
\text { estándar }\end{array}$ & $\begin{array}{c}\text { Coeficiente } \\
\text { de } \\
\text { variación }\end{array}$ & $\begin{array}{l}\text { Tasa de } \\
\text { crecimiento } \\
\text { anmal (\%) }\end{array}$ & $" R »$ & $" \mathrm{R}^{2} »$ & $\begin{array}{c}\text { Nivel } \\
\text { de } \\
\text { significacion }\end{array}$ \\
\hline $1501-1525$ & 19,5 & 2,98 & 15,56 & 0,872 & 0,422 & 0,178 & 0,025 \\
\hline $1526-1550 \ldots \ldots \ldots$ & 26,33 & 4,71 & 17,89 & 1,300 & 0,530 & 0,281 & 0,005 \\
\hline $1551-1575 \ldots \ldots \ldots$ & 44,28 & 12,96 & 29,27 & 2,803 & 0,773 & 0,597 & 0,005 \\
\hline $1576-1600 \ldots \ldots \ldots$ & 69,30 & 14,87 & 21,46 & 2,190 & 0,686 & 0,470 & 0,005 \\
\hline $1601-1625 \ldots \ldots \ldots$ & 100,06 & 69,99 & 69,94 & 2,640 & 0,467 & 0,218 & 0,010 \\
\hline $1626-1650 \ldots \ldots$. & 130,75 & 57,47 & 43,95 & $-0,124$ & 0,226 & 0,051 & 0,100 \\
\hline $1651-1675$ & 69,55 & 15,82 & 22,75 & 0,153 & 0,055 & 0,003 & 0,100 \\
\hline $1676-1700$ & 109,36 & 28,47 & 26,03 & 0,136 & 0,387 & 0,150 & 0,050 \\
\hline
\end{tabular}

FUENTE: Phelps Brown y Hopkins (1957), pp. 303-05.

GRAFICO A-1

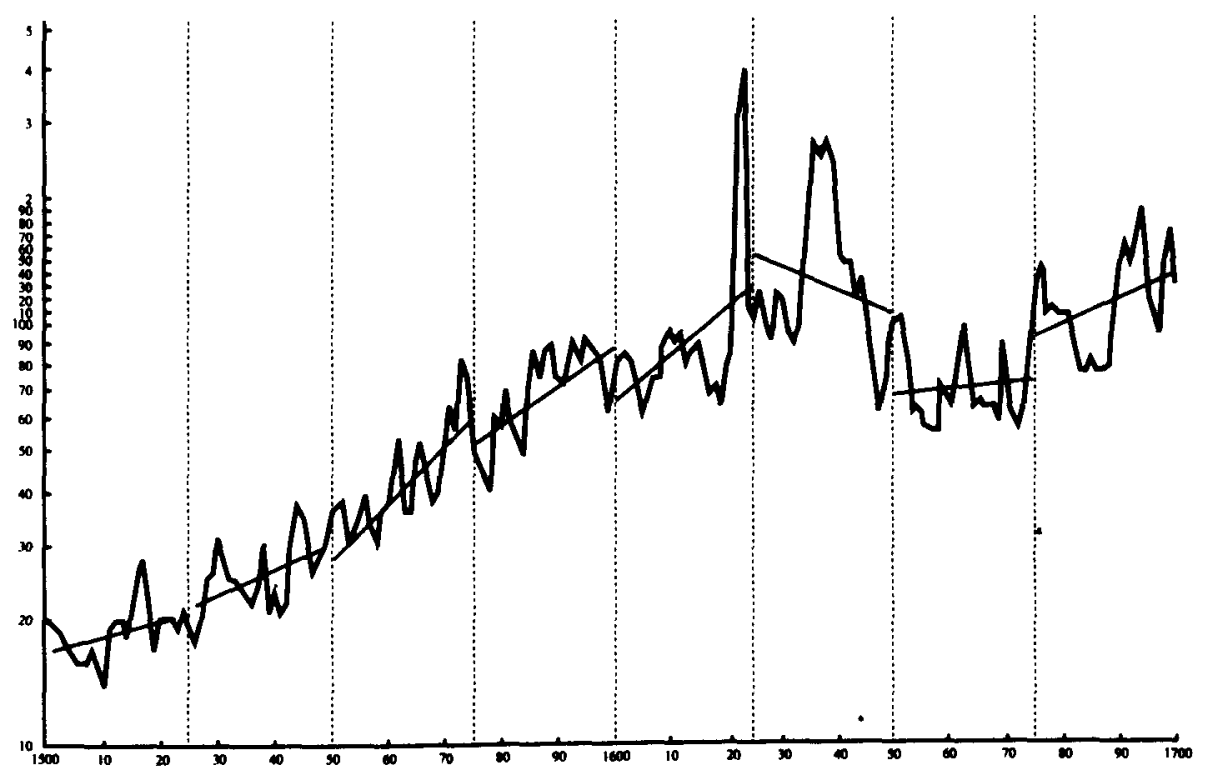




\section{CUADRO A-2}

Amberes: Análisis de Regresión del Indice Ponderado

de Precios de Consumo, 1501-1700

Base, media $1601-25=100 \quad Y=a \cdot b^{x}$

\begin{tabular}{|c|c|c|c|c|c|c|c|}
\hline Años & Media & $\begin{array}{l}\text { Desviación } \\
\text { estándar }\end{array}$ & $\begin{array}{c}\text { Coeficiente } \\
\text { de } \\
\text { variacion }\end{array}$ & $\begin{array}{l}\text { Tasa de } \\
\text { crecimiento } \\
\text { anual }(\%)\end{array}$ & «R» & " $R^{2} »$ & $\begin{array}{c}\text { Nivel } \\
\text { de } \\
\text { significación }\end{array}$ \\
\hline $1501-1525 \quad \ldots \ldots \ldots$ & 21,32 & 4,02 & 18,85 & 1,904 & 0,792 & 0,628 & 0,005 \\
\hline $1526-1550 \ldots$ & 28,20 & 3,28 & 11,63 & 0,855 & 0,548 & 0,300 & 0,005 \\
\hline 1551-1575 $\ldots \ldots \ldots$ & 48,96 & 9,74 & 19,89 & 2,052 & 0,794 & 0,630 & 0,005 \\
\hline $1576-1600 \ldots \ldots \ldots$ & 100,92 & 30,40 & 30,12 & 2,008 & 0,541 & 0,293 & 0,005 \\
\hline $1601-1625 \ldots$ & 100,00 & 17,30 & 17,30 & 1,117 & 0,512 & 0,263 & 0,005 \\
\hline $1626-1650 \ldots \ldots \ldots$ & 145,8 & 12,26 & 8,45 & 0,571 & 0,513 & 0,263 & 0,005 \\
\hline $1651-1675 \ldots \ldots \ldots$ & 126,88 & 18,93 & 14,92 & $-0,625$ & 0,330 & 0,109 & 0,100 \\
\hline $1676-1700 \ldots \ldots \ldots$ & 122,20 & 23,03 & 18,85 & 1,103 & 0,453 & 0,205 & 0,025 \\
\hline
\end{tabular}

FUENTE: Van der Wee (1975), pp. 436-47.

\section{GRAFICO A-2}

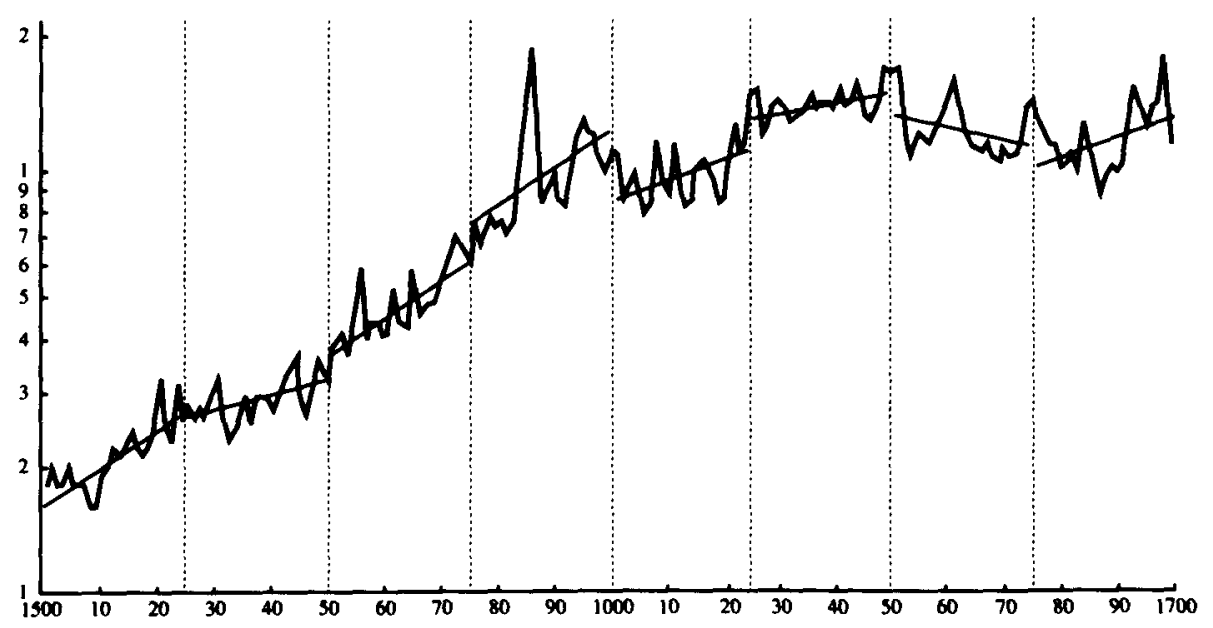




\section{CUADRO A-3}

Augsburgo: Análisis de Regresión del Indice Ponderado de Precios de Consumo, 1501-1700

$$
\text { Base, media } 1601-25=100 \quad Y=a \cdot b^{x}
$$

\begin{tabular}{|c|c|c|c|c|c|c|c|}
\hline Años & Media & $\begin{array}{l}\text { Desviación } \\
\text { eständar }\end{array}$ & $\begin{array}{c}\text { Coeficiente } \\
\text { de } \\
\text { variación }\end{array}$ & $\begin{array}{c}\text { Tasa de } \\
\text { crecimiento } \\
\text { anual (\%) }\end{array}$ & «R» & $" R^{2} »$ & $\begin{array}{c}\text { Nivel } \\
\text { de } \\
\text { significación }\end{array}$ \\
\hline $1501-1525 \quad \ldots \ldots \ldots$ & 22,51 & 2,20 & 9,77 & $-0,245$ & 0,195 & 0,038 & 0,100 \\
\hline $1526-1550 \quad \ldots \ldots$. & 34,90 & 5,20 & 14,90 & 0,886 & 0,410 & 0,168 & 0,025 \\
\hline 1551-1575 $\ldots \ldots \ldots$ & 51,64 & 14,40 & 27,89 & 2,682 & 0,772 & 0,596 & 0,005 \\
\hline $1576-1600 \quad \ldots \ldots \ldots$ & 63,96 & 9,14 & 14,29 & 1,365 & 0,683 & 0,446 & 0,005 \\
\hline $1601-1625 \ldots \ldots \ldots$ & 100,08 & 57,55 & 57,50 & 3,178 & 0,641 & 0,411 & 0,005 \\
\hline $1626-1650 \ldots \ldots \ldots$ & 120,11 & 47,55 & 39,59 & $-0,163$ & 0,369 & 0,136 & 0,050 \\
\hline $1651-1675 \ldots \ldots$. & 70,06 & 8,59 & 12,26 & $-0,327$ & 0,197 & 0,039 & 0,100 \\
\hline $1676-1700 \ldots \ldots \ldots$ & 83,69 & 16,28 & 19,45 & 1,665 & 0,659 & 0,434 & 0,005 \\
\hline
\end{tabular}

FUENTE: Phelps Brown y Hopkins (1959), pp. 35-37.

\section{GRAFICO A-3}

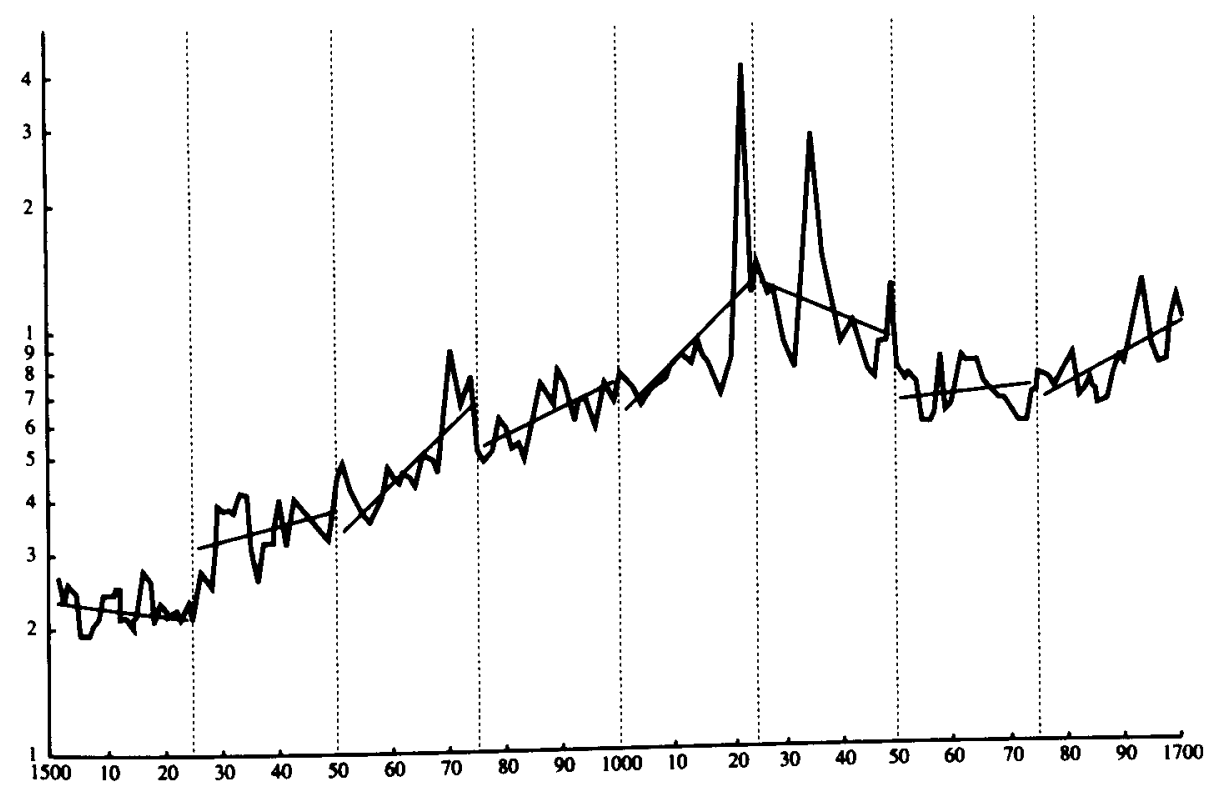




\section{CUADRO A-4}

Castilla la Nueva: Análisis de Regresión del Indice Ponderado de Precios de Consumo, 1501-1700

Base, media $1601-25=100 \quad Y=a \cdot b^{x}$

\begin{tabular}{|c|c|c|c|c|c|c|c|}
\hline Años & Media & $\begin{array}{l}\text { Desviación } \\
\text { estándar }\end{array}$ & $\begin{array}{c}\text { Coeficiente } \\
\text { de } \\
\text { variación }\end{array}$ & $\begin{array}{c}\text { Tasa de } \\
\text { crecimiento } \\
\text { anual }(\%)\end{array}$ & «R» & " $\mathrm{R}^{2} \|$ & $\begin{array}{c}\text { Nivel } \\
\text { de } \\
\text { significacion }\end{array}$ \\
\hline $1501-1525$ & 23,35 & 3,83 & 16,40 & 0,794 & 0,362 & 0,131 & 0,005 \\
\hline $1526-1550$ & 33,13 & 7,26 & 21,91 & 2,276 & 0,798 & 0,637 & 0,005 \\
\hline $1551-1575 \ldots \ldots \ldots$ & 52,10 & 8,80 & 16,89 & 2,101 & 0,851 & 0,724 & 0,005 \\
\hline $1576-1600 \ldots \ldots \ldots$ & 77,3 & 10,50 & 13,59 & 1,102 & 0,629 & 0,396 & 0,005 \\
\hline $1601-1625$ & 100,0 & 14,40 & 14,40 & 0,915 & 0,451 & 0,203 & 0,025 \\
\hline $1626-1650 \ldots \ldots$ & 132,60 & 18,40 & 13,88 & 1,084 & 0,596 & 0,355 & 0,005 \\
\hline $1651-1675 \ldots \ldots \ldots$ & 187,40 & 33,54 & 17,90 & 0,162 & 0,671 & 0,450 & 0,005 \\
\hline $1676-1700 \ldots \ldots$. & 162,00 & 47,80 & 29,51 & $-2,410$ & 0,666 & 0,444 & 0,005 \\
\hline
\end{tabular}

FUENTE: Cuadro 2.

\section{GRAFICO A-4}

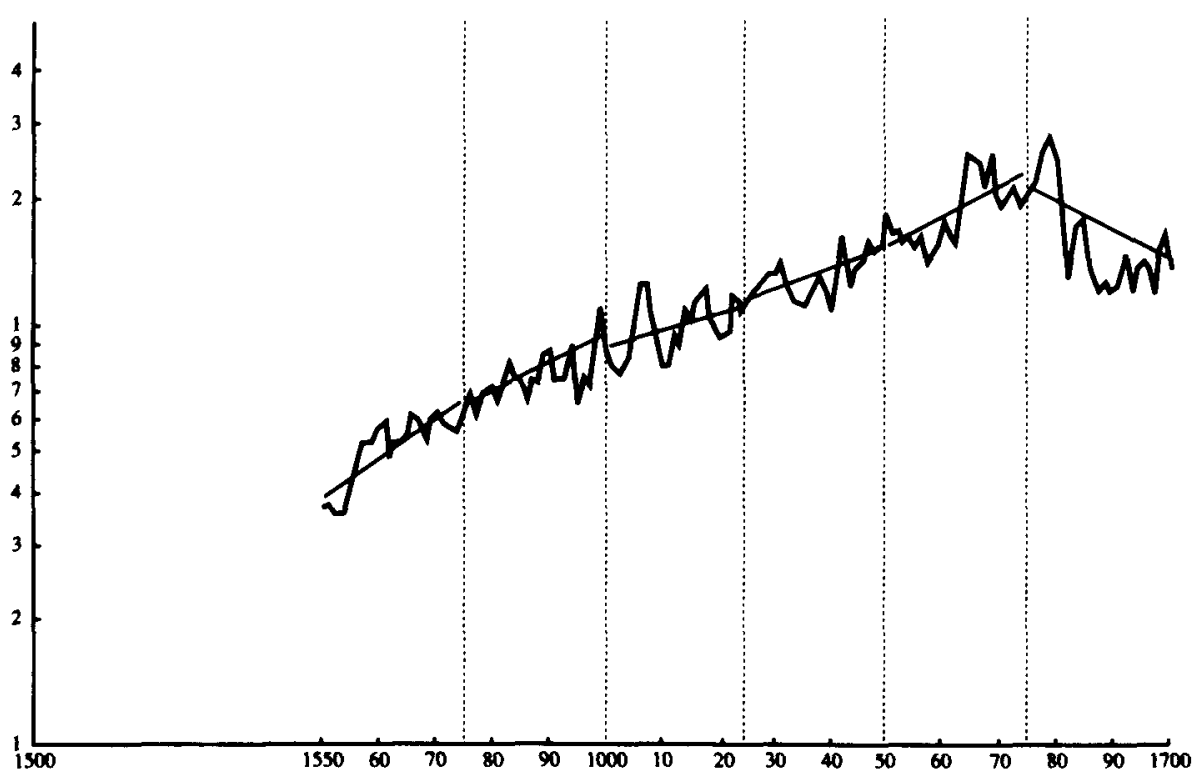




\section{CUADRO A-5}

Sur de Inglaterra: Análisis de Regresión del Indice Ponderado de Precios de Consumo, 1501-1700

Base, media $1601-25=100 \quad Y=a \cdot b^{x}$

\begin{tabular}{|c|c|c|c|c|c|c|c|}
\hline Años & Media & $\begin{array}{c}\text { Desviación } \\
\text { estaindar }\end{array}$ & $\begin{array}{c}\text { Coeficiente } \\
\text { de } \\
\text { variación }\end{array}$ & $\begin{array}{c}\text { Tasa de } \\
\text { crecimiento } \\
\text { anual (\%) }\end{array}$ & « & $\| R^{2} »$ & $\begin{array}{c}\text { Nivel } \\
\text { de } \\
\text { significación }\end{array}$ \\
\hline $1501-1525$ & 23,02 & 3,64 & 15,81 & 1,379 & 0,671 & 0,450 & 0,005 \\
\hline $1526-1550 \ldots \ldots \ldots$ & 34,27 & 6,52 & 19,03 & 1,710 & 0,698 & 0,487 & 0,005 \\
\hline $1551-1575 \ldots \ldots \ldots$ & 56,87 & 7,71 & 13,56 & 0,224 & 0,134 & 0,018 & 0,100 \\
\hline $1576-1600 \ldots \ldots$ & 79,51 & 18,02 & 22,66 & 2,123 & 0,753 & 0,567 & 0,005 \\
\hline $1601-1625 \ldots \ldots \ldots$ & 100,10 & 9,11 & 9,10 & 0,647 & 0,504 & 0,254 & 0,010 \\
\hline $1626-1650 \ldots \ldots \ldots$ & 119,65 & 18,09 & 15,12 & 1,168 & 0,591 & 0,349 & 0,005 \\
\hline 1651-1675 ..... & 123,10 & 11,52 & 9,36 & $-0,053$ & 0,316 & 0,100 & 0,100 \\
\hline $1676-1700$ & 122,03 & 14,40 & 11,80 & 0,555 & 0,341 & 0,116 & 0,050 \\
\hline
\end{tabular}

FUENTE: Phelps Brown y Hopkins (1956).

GRAFICO A-5

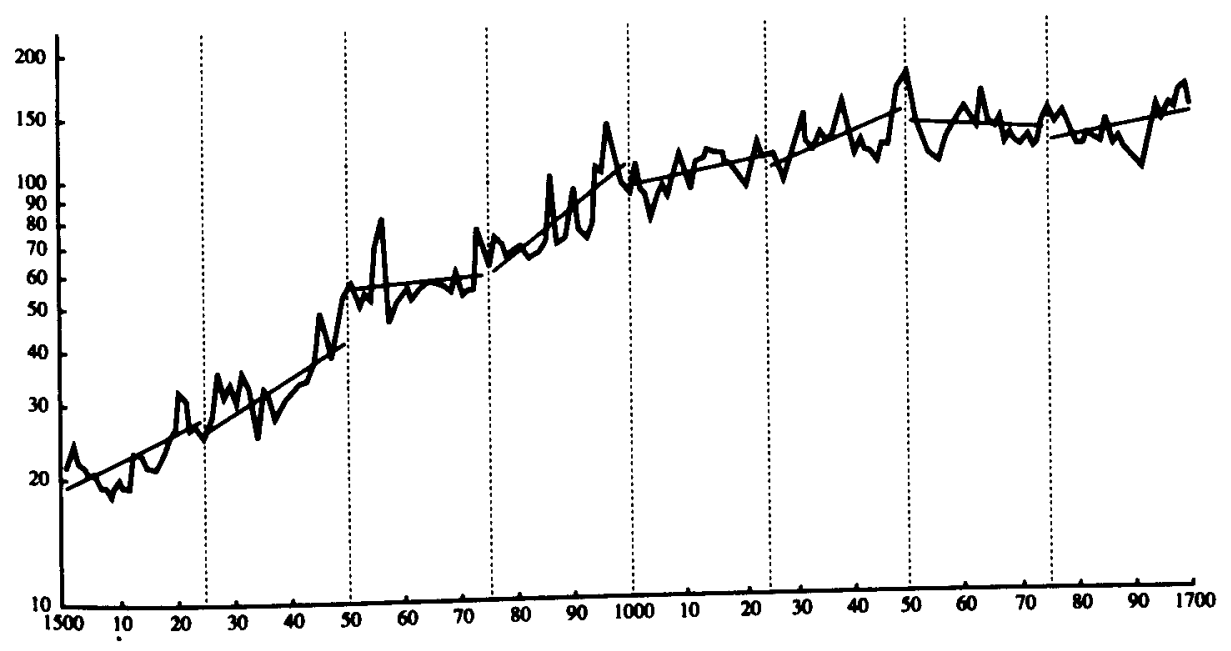




\section{CUADRO A-6}

Valencia: Análisis de Regresión del Indice Ponderado de Precios de Consumo, 1501-1700

$$
\text { Base, media } 1601-25=100 \quad Y=a \cdot b^{x}
$$

\begin{tabular}{|c|c|c|c|c|c|c|c|}
\hline Años & Media & $\begin{array}{c}\text { Desviación } \\
\text { estándar }\end{array}$ & $\begin{array}{c}\text { Coeficiente } \\
\text { de } \\
\text { variacion }\end{array}$ & $\begin{array}{l}\text { Tasa de } \\
\text { crecimiento } \\
\text { anxal (\%) }\end{array}$ & «R» & $\| R^{2} »$ & $\begin{array}{c}\text { Nivel } \\
\text { de } \\
\text { significación }\end{array}$ \\
\hline $1501-1525$ & 32,7 & 4,00 & 12,23 & 0,475 & 0,300 & 0,090 & 0,100 \\
\hline $1526-1550 \ldots \ldots$. & 39,5 & 3,33 & 8,43 & 0,837 & 0,748 & 0,560 & 0,005 \\
\hline 1551-1575 $\ldots \ldots \ldots$ & 62,13 & 7,87 & 12,67 & 1,518 & 0,882 & 0,778 & 0,005 \\
\hline $1576-1600 \ldots \ldots$. & 86,22 & 9,34 & 10,83 & 1,175 & 0,801 & 0,641 & 0,005 \\
\hline 1601-1625 $\ldots$ & 100,06 & 6,04 & 6,04 & $-0,150$ & 0,190 & 0,036 & 0,100 \\
\hline $1626-1650 \ldots \ldots \ldots$ & 115,93 & 9,14 & 7,88 & 0,352 & 0,330 & 0,109 & 0,100 \\
\hline 1651-1675 $\ldots \ldots \ldots$ & $\ldots$ & $\ldots$ & ... & $\ldots$ & $\ldots$ & $\ldots$ & $\ldots$ \\
\hline $1676-1700 \ldots \ldots$. & $\ldots$ & $\ldots$ & $\ldots$ & $\ldots$ & $\ldots$ & $\ldots$ & $\ldots$ \\
\hline
\end{tabular}

.. No disponible.

Fuente: Phelps Brown y Hopkins (1959), pp. 35-37.

\section{GRAFICO A-6}

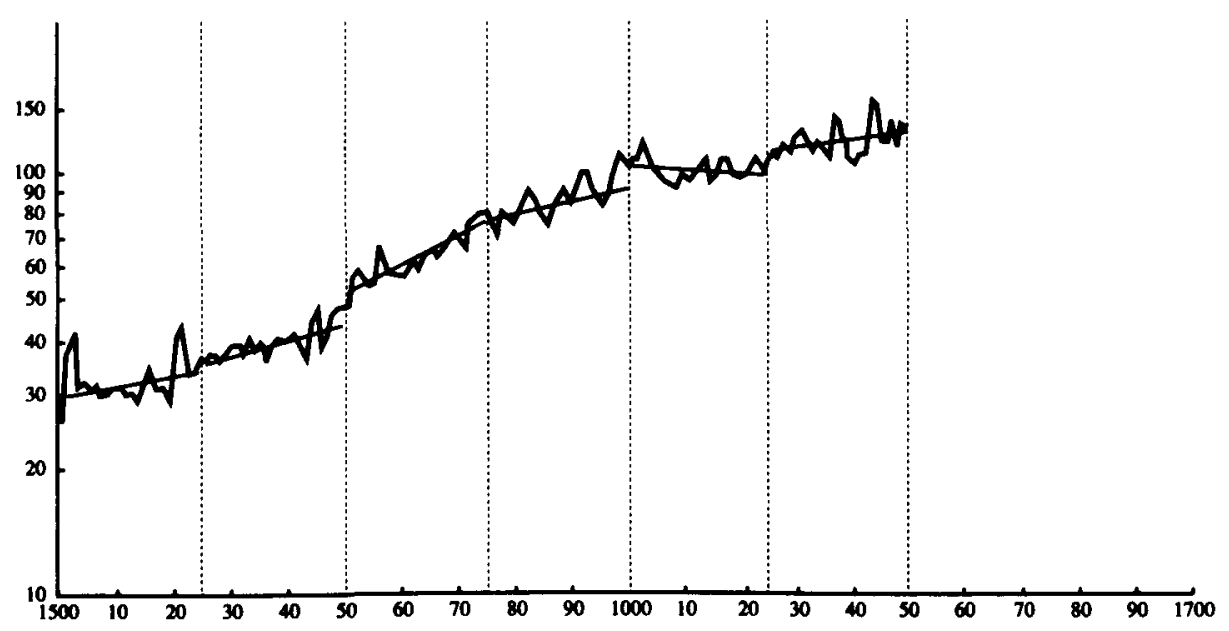




\section{CUADRO A-7}

Viena: Análisis de Regresión del Indice Ponderado de Precios de Consumo, 1501-1700

Base, media $1601-25=100 \quad Y=a \cdot b^{x}$

\begin{tabular}{|c|c|c|c|c|c|c|c|}
\hline Años & Media & $\begin{array}{l}\text { Desviación } \\
\text { estándar }\end{array}$ & $\begin{array}{c}\text { Coeficiente } \\
\text { de } \\
\text { variacion }\end{array}$ & $\begin{array}{c}\text { Tasa de } \\
\text { crecimiento } \\
\text { anual (\%) }\end{array}$ & "R» & $\| R^{2} »$ & $\begin{array}{c}\text { Nivel } \\
\text { de } \\
\text { significación }\end{array}$ \\
\hline $1501-1525$ & 18,56 & 1,16 & 6,25 & 0,420 & 0,500 & 0,250 & 0,025 \\
\hline $1526-1550$ & 27,36 & 3,47 & 12,68 & 1,090 & 0,622 & 0,387 & 0,005 \\
\hline $1551-1575 \ldots$ & 40,31 & 8,31 & 20,61 & 2,224 & 0,822 & 0,676 & 0,005 \\
\hline $1576-1600 \ldots \ldots$. & 49,80 & 10,74 & 21,57 & 2,355 & 0,878 & 0,771 & 0,005 \\
\hline $1601-1625 \ldots \ldots \ldots$ & 99,97 & 71,74 & 71,76 & 4,026 & 0,668 & 0,446 & 0,005 \\
\hline $1626-1650$ & 88,13 & 8,93 & 10,13 & 0,613 & 0,427 & 0,182 & 0,025 \\
\hline $1651-1675$ & 80,88 & 13,74 & 16,99 & $-0,189$ & 0,089 & 0,008 & 0,100 \\
\hline $1676-1700 \ldots \ldots \ldots$ & 109,93 & 25,61 & 23,30 & 2,890 & 0,844 & 0,712 & 0,005 \\
\hline
\end{tabular}

FuENTE: Phelps Brown y Hopkins (1959), pp. 35-37.

\section{GRAFICO A-7}

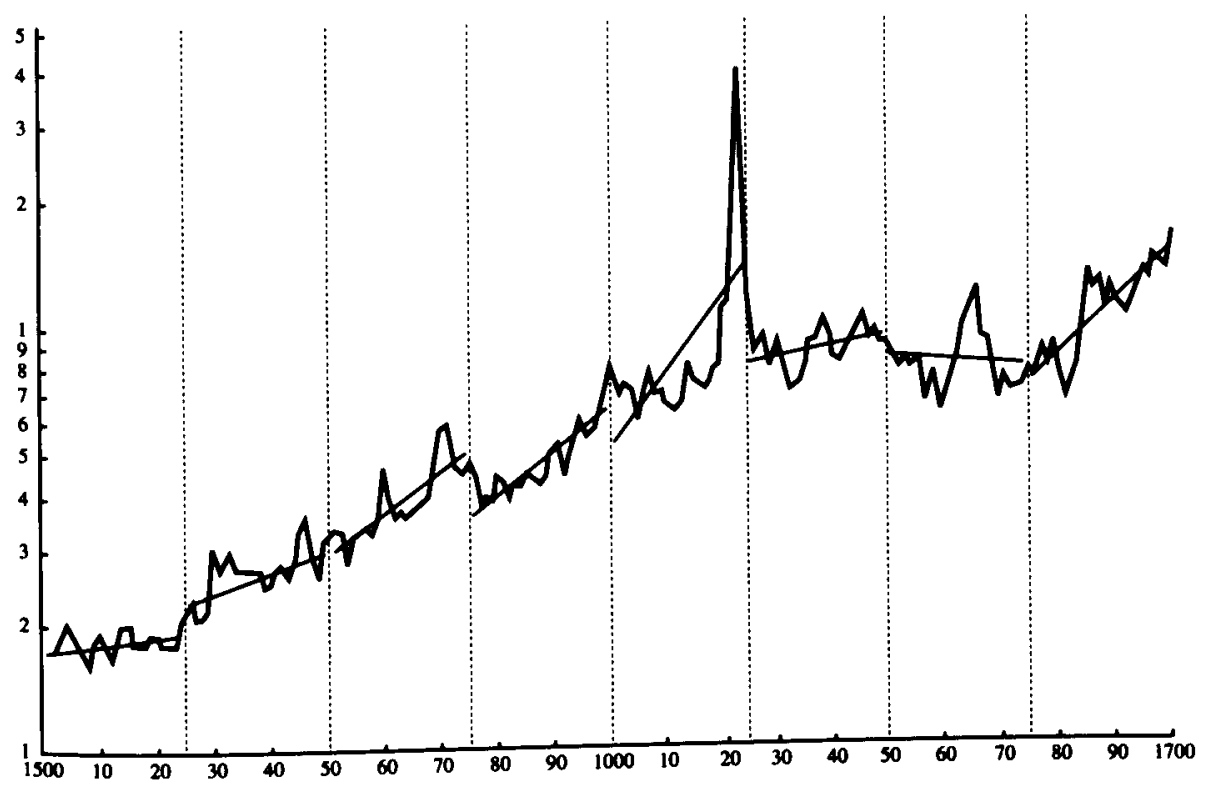




\section{APENDICE B. Relaciones de cambio intersectorial (Precios agrarios / Precios de manufacturas)}

\section{CUADRO B-1}

Castilla la Nueva: Relaciones de cambio intersectorial, 1551-1640

(Base, $1601-1625=100$ )

\begin{tabular}{|c|c|c|c|c|c|c|}
\hline Años & R.C.I. & Años & & R.C.I. & Años & R.C.I. \\
\hline 551 & $\ldots$ n.d & 1581 & & 78 & 1611 & 63 \\
\hline 1552 & $\ldots$ n.d & 1582 & & 89 & 1612 & 86 \\
\hline 1553 & ....n.d & 1583 & & .. 116 & 1613 & \\
\hline 1554 & $\ldots \quad 42$ & 1584 & & .. 91 & 1614 & . \\
\hline 1555 & . 54 & 1585 & & 8 & 1615 & 113 \\
\hline 1556 & $\ldots \cdot 67$ & 1586 & & 00 & 616 & .. 119 \\
\hline 1557 & $\ldots 85$ & 1587 & & 59 & 1617 & .. 186 \\
\hline 1558 & 90 & 1588 & & 71 & 8 & 108 \\
\hline 1559 & $\ldots \quad 87$ & 1589 & & . & 1619 & 92 \\
\hline 1560 & ….......... 73 & 1590 & & 75 & 1620 & 78 \\
\hline 1561 & 83 & 1591 & & 84 & 1 & 92 \\
\hline 1562 & $\ldots \ldots, 119$ & 1592 & & & 2 & 90 \\
\hline 563 & $\ldots \quad 54$ & 1593 & & .. & 1623 & 109 \\
\hline 1564 & 60 & 1594 & & . 10 & 1624 & 124 \\
\hline 1565 & $\begin{array}{ll}\ldots & 5\end{array}$ & 1595 & & & 5 & .. 106 \\
\hline 566 & $\begin{array}{ll}\ldots \ldots & 79\end{array}$ & 1596 & & 73 & 1626 &. .103 \\
\hline 1567 & …... 89 & 1597 & & 8 & 1627 & 93 \\
\hline 1568 & $\ldots \ldots 86$ & 1598 & & 95 & 1628 & 112 \\
\hline 1569 & $\ldots 70$ & 1599 & & . 112 & 1629 & 95 \\
\hline 1570 & ….......... 75 & 1600 & & 84 & 1630 & 104 \\
\hline $8 / 1$ & 74 & 1601 & & & & 103 \\
\hline 1572 & $\ldots 71$ & 1602 & & 6 & 1632 & 93 \\
\hline 1573 & 58 & 1603 & & 6 & 1633 & 80 \\
\hline 1574 & 63 & 1604 & & 76 & 1634 & 87 \\
\hline 1575 & 71 & 1605 & & . 104 & 1635 & 78 \\
\hline 1576 & 79 & 1606 & & . 139 & 1636 & 86 \\
\hline 1577 & 71 & 1607 & & . 155 & 1637 & 85 \\
\hline 1578 & 76 & 1608 & & . 122 & 1638 & 89 \\
\hline 1579 & 78 & 1609 & & . 104 & 1639 & 81 \\
\hline 1580 & 76 & 1610 & 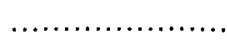 & 70 & 1640 & 78 \\
\hline
\end{tabular}

n.d.: no disponible.

FUENTES: Hamilton (1965), pp. 391-92, y Cuadro B-2. 


\section{CUADRO B-2}

Castilla la Nueva: Indice de precios de manufacturas

(Base, $1601-1625=100$ )

\begin{tabular}{|c|c|c|c|c|c|c|c|c|}
\hline Años & & Indice & Años & & Indice & Años & & Indice \\
\hline 551 & & n.d & 1581 & & 77 & 1611 & & 101 \\
\hline 1552 & & n.d & 1582 & & 71 & 1612 & & 98 \\
\hline 1553 & & 52 & 1583 & & 81 & 1613 & & 95 \\
\hline 1554 & & 52 & 1584 & & 77 & 1614 & & 94 \\
\hline 1555 & $\ldots$ & 52 & 1585 & & 78 & 1615 & & 98 \\
\hline 1556 & & 52 & 1586 & & 87 & 1616 & & 106 \\
\hline 1557 & & 53 & 1587 & & 87 & 1617 & & 100 \\
\hline 1558 & & 51 & 1588 & & 83 & 1618 & & 99 \\
\hline 1559 & & 53 & 1589 & & 85 & 1619 & & 98 \\
\hline 1560 & & 64 & 1590 & & 84 & 1620 & & 97 \\
\hline 1561 & & 66 & 1591 & & 81 & 1621 & & 96 \\
\hline 1562 & & 63 & 1592 & & 88 & 1622 & & 91 \\
\hline 1563 & & 65 & 1593 & & 86 & 1623 & & 106 \\
\hline 1564 & & 63 & 1594 & & 91 & 1624 & & 92 \\
\hline 1565 & & 63 & 1595 & & 86 & 1625 & & . 106 \\
\hline 1566 & & 57 & 1596 & & 82 & 1626 & & . 106 \\
\hline 1567 & & 61 & 1597 & & 83 & 1627 & & . 116 \\
\hline 1568 & & 63 & 1598 & & 86 & 1628 & & . 117 \\
\hline 1569 & & 60 & 1599 & & 90 & 1629 & & . 125 \\
\hline 1570 & & 60 & 1600 & & 108 & 1630 & & 119 \\
\hline 1571 & & 65 & 1601 & & 110 & 1631 & & 148 \\
\hline 1572 & & 73 & 1602 & & 108 & 1632 & & . 119 \\
\hline 1573 & & 73 & 1603 & & 106 & 1633 & & . 118 \\
\hline 1574 & & 64 & 1604 & & 100 & 1634 & & . 114 \\
\hline 1575 & & 66 & 1605 & & 100 & 1635 & & . 125 \\
\hline 1576 & & 70 & 1606 & & 102 & 1636 & & . 126 \\
\hline 1577 & & 78 & 1607 & & 96 & 1637 & & . 128 \\
\hline 1578 & & 76 & 1608 & & 99 & 1638 & & . 124 \\
\hline 1579 & & 80 & 1609 & & 93 & 1639 & & . 127 \\
\hline 1580 & & 74 & 1610 & & 106 & 1640 & & 125 \\
\hline
\end{tabular}

n.d.: no disponible.

FUeNTE: Hamilton (1965), Apéndices IV y V.

Composición: Ladrillos, velas, carbón vegetal, algodón, cáñamo, cal, clavos, papel, yeso, almidón, azúcar, hilo, cera. 


\section{CUADRO B-3}

Sur de Inglaterra: Relaciones de cambio intersectorial, 1551-1649 (Base, $1601-1625=100$ )

\begin{tabular}{|c|c|c|c|c|c|c|}
\hline Años & N.. R.C.I. & Años & & R.C.I. & Años & R.C.I. \\
\hline 1551 & 82 & 1581 & & 89 & 1611 & 110 \\
\hline 1552 & ... 72 & 1582 & & 88 & 1612 & 117 \\
\hline 1553 & ... 74 & 1583 & & 77 & 1613 & 113 \\
\hline 1554 & $\ldots 82$ & 1584 & & 65 & 1614 & 100 \\
\hline 1555 & $\ldots .131$ & 1585 & & 107 & 1615 & 118 \\
\hline 1556 & $\ldots \ldots \ldots \ldots \ldots \ldots \ldots, 142$ & 1586 & & .. 127 & 1616 & .. 107 \\
\hline 1557 & $\ldots \quad 58$ & 1587 & & 69 & 1617 & 107 \\
\hline 1558 & $\ldots \quad 68$ & 1588 & & 70 & 1618 & 97 \\
\hline 1559 & 71 & 1589 & & 100 & 1619 & 87 \\
\hline 1560 & n.............. 72 & 1590 & & .. 116 & 1620 & 70 \\
\hline 1561 & .. 64 & 1591 & & 84 & 1621 & 108 \\
\hline 1562 & 80 & 1592 & & 55 & 1622 & .. 121 \\
\hline 1563 & $\ldots 72$ & 1593 & & 65 & 1623 & .. 105 \\
\hline 1564 & $\ldots \quad 54$ & 1594 & & 112 & 1624 & .. 104 \\
\hline 1565 & 72 & 1595 & & 114 & 1625 & 121 \\
\hline 1566 & ...... & 1596 & & .. 170 & 1626 & 99 \\
\hline 1567 & $\ldots .$. & 1597 & & . 131 & 1627 & 77 \\
\hline 1568 & 79 & 1598 & & 85 & 1628 & .. 104 \\
\hline 1569 & 59 & 1599 & & 96 & 1629 & .. 102 \\
\hline 1570 & 65 & 1600 & & . 131 & 1630 & .. 154 \\
\hline 1571 & 65 & 1601 & & 99 & 1631 & 96 \\
\hline 1572 & 76 & 1602 & & 83 & 1632 & .. 116 \\
\hline 1573 & 100 & 1603 & & 73 & 1633 & $\ldots 120$ \\
\hline 1574 & 71 & 1604 & & 87 & 1634 & 111 \\
\hline 1575 & 81 & 1605 & & 95 & 1635 & 98 \\
\hline 1576 & 73 & 1606 & & 84 & 1636 & 107 \\
\hline 1577 & 80 & 1607 & & 93 & 1637 & 146 \\
\hline 1578 & $\ldots .$. & 1608 & & 106 & 1638 & 107 \\
\hline 1579 & 84 & 1609 & & 103 & 1639 & $\begin{array}{ll}\ldots . . & 81\end{array}$ \\
\hline 1580 & …..... 91 & 1610 & .. & 88 & 1640 & .... 99 \\
\hline
\end{tabular}

Fuentes: Bowden (1967b), cuadro XI, y Donghty (1975), Appendix. 


\section{CUADRO B-4}

Brabante: Relaciones de cambio intersectorial, 1551-1600

(Base: media $1551-1600=100$ )

\begin{tabular}{|c|c|c|c|c|}
\hline & Años & $\begin{array}{l}\text { Indice precios } \\
\text { de cereales }\end{array}$ & $\begin{array}{c}\text { Indice precios } \\
\text { industriales }\end{array}$ & R.C.I. \\
\hline $\begin{array}{l}1551 \\
1952 \\
1553 \\
1554 \\
1555 \\
1556 \\
1557 \\
1558 \\
1559\end{array}$ & 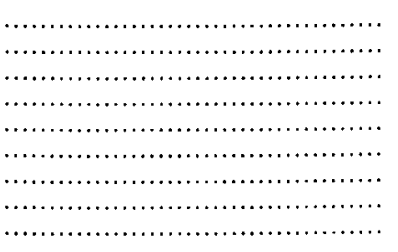 & $\begin{array}{r}103 \\
96 \\
102 \\
81 \\
97 \\
174 \\
84 \\
89 \\
91\end{array}$ & $\begin{array}{r}79 \\
91 \\
94 \\
101 \\
103 \\
102 \\
91 \\
112 \\
116\end{array}$ & $\begin{array}{r}134 \\
105 \\
109 \\
80 \\
94 \\
171 \\
92 \\
79 \\
78\end{array}$ \\
\hline $\begin{array}{l}1560 \\
1561 \\
1562 \\
1563 \\
1564 \\
1565 \\
1566 \\
1567 \\
1568 \\
1569\end{array}$ & 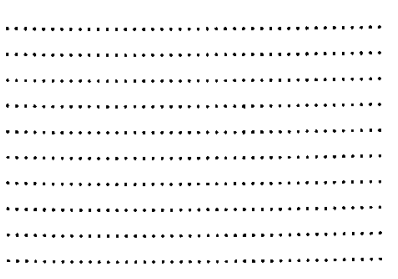 & $\begin{array}{r}82 \\
87 \\
130 \\
93 \\
91 \\
163 \\
104 \\
103 \\
110 \\
110\end{array}$ & $\begin{array}{r}114 \\
107 \\
99 \\
104 \\
133 \\
128 \\
118 \\
133 \\
125 \\
134\end{array}$ & $\begin{array}{r}72 \\
81 \\
131 \\
89 \\
68 \\
127 \\
88 \\
77 \\
88 \\
82\end{array}$ \\
\hline $\begin{array}{l}1570 \\
1571 \\
1572 \\
1573 \\
1574 \\
1575 \\
1576 \\
1577 \\
1578 \\
1579\end{array}$ & 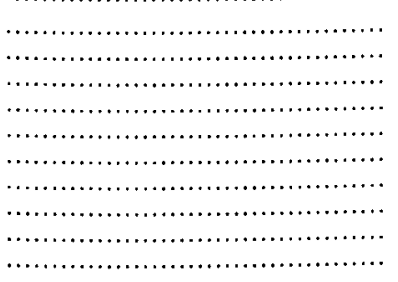 & $\begin{array}{l}116 \\
149 \\
177 \\
192 \\
157 \\
130 \\
199 \\
173 \\
171 \\
187\end{array}$ & $\begin{array}{l}137 \\
131 \\
139 \\
173 \\
180 \\
181 \\
181 \\
165 \\
171 \\
202\end{array}$ & $\begin{array}{r}85 \\
114 \\
127 \\
111 \\
89 \\
72 \\
110 \\
105 \\
110 \\
93\end{array}$ \\
\hline $\begin{array}{l}1580 \\
1581 \\
1582 \\
1583 \\
1584 \\
1585 \\
1586 \\
1587 \\
1588 \\
1589\end{array}$ & 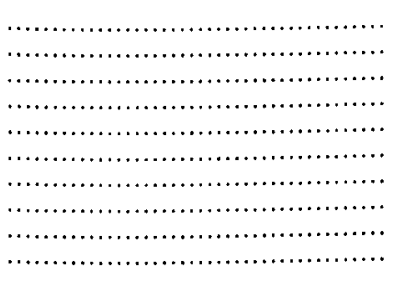 & $\begin{array}{l}177 \\
180 \\
161 \\
167 \\
202 \\
480 \\
736 \\
625 \\
170 \\
206\end{array}$ & $\begin{array}{l}199 \\
184 \\
202 \\
205 \\
215 \\
263 \\
330 \\
296 \\
259 \\
254\end{array}$ & $\begin{array}{r}89 \\
98 \\
80 \\
81 \\
94 \\
183 \\
223 \\
211 \\
66 \\
81\end{array}$ \\
\hline $\begin{array}{l}1590 \\
1591 \\
1592 \\
1593 \\
1594 \\
1595 \\
1596 \\
1597 \\
1598 \\
1599 \\
1600 \\
\end{array}$ & 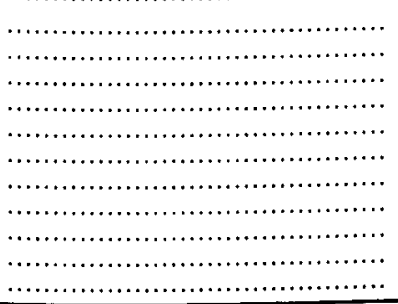 & $\begin{array}{l}261 \\
175 \\
179 \\
243 \\
337 \\
398 \\
345 \\
314 \\
263 \\
236 \\
325\end{array}$ & $\begin{array}{l}214 \\
227 \\
231 \\
255 \\
268 \\
273 \\
281 \\
318 \\
307 \\
303 \\
337 \\
\end{array}$ & $\begin{array}{r}122 \\
77 \\
74 \\
95 \\
126 \\
146 \\
123 \\
99 \\
86 \\
78 \\
96 \\
\end{array}$ \\
\hline
\end{tabular}

\section{NOTAS:}

Incluye: Cebada, avena y centeno, en Amberes.

b Incluye: Velas de cera, carbón vegetal, ladrillos, cal, tejidos de lana, arenque, azúcar, sal y cera.

Fuente: Van der Wee (1963), Part II: «Statistical Data», pp. 169-333. 


\section{CUADRO B-5}

Brabante Occidental: Relaciones de cambio intersectorial, 1601-1640 (Base: media 1601-1610 $=100$ )

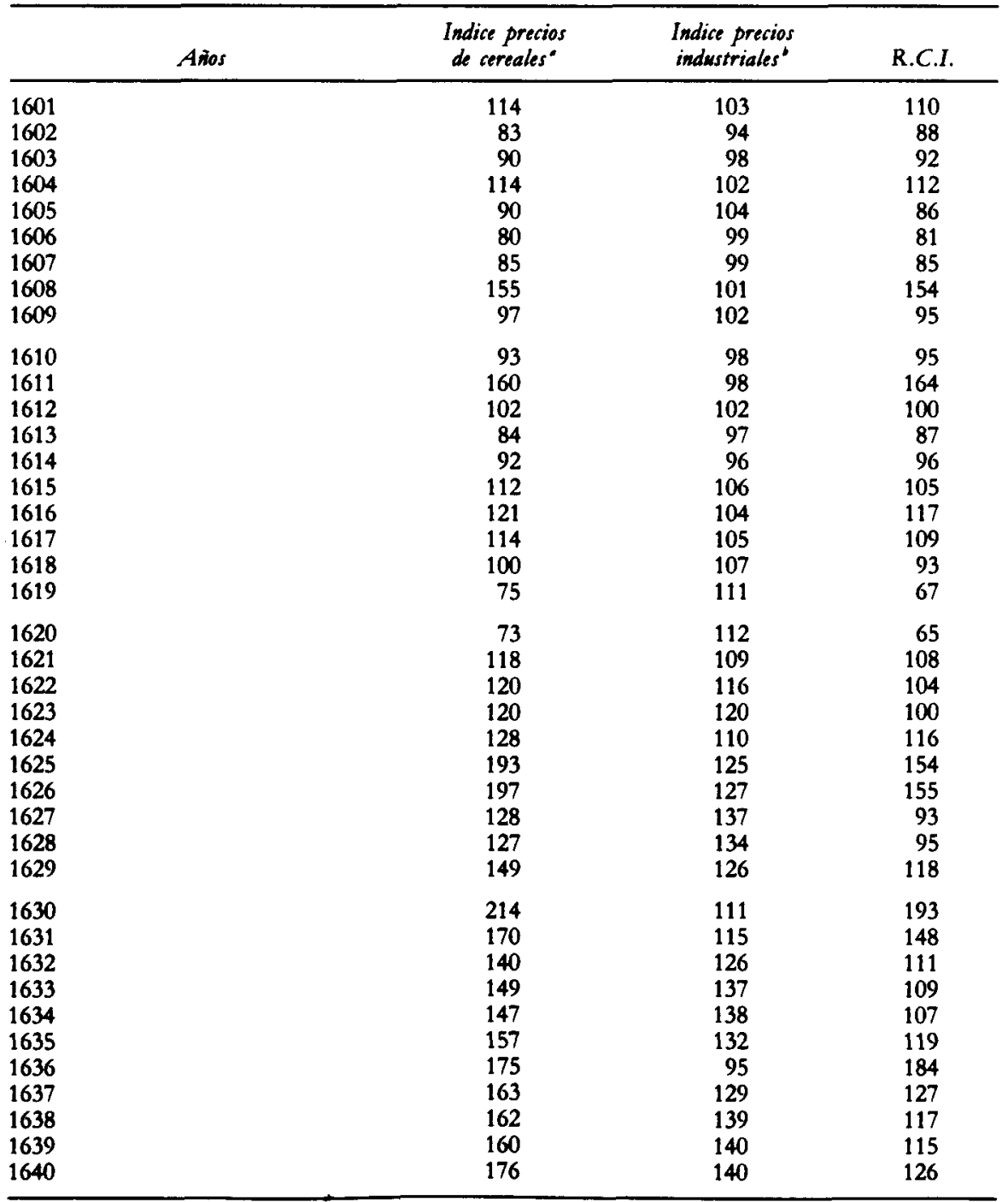

Notas:

- Incluye: Cebada y centeno.

b Incluye: Arenque, carbón vegetal, velas y tejidos de algodón.

Fuente: Van der Wee (1975), pp. 436-447. 


\section{BIBLIOGRAFIA}

Bowden, P. (1967a), «Agricultural Prices, Farm Profits, and Rents», en J. Thirsk (ed.), The Agrarian History of England and Wales. Cambridge: Cambridge University Press.

- (1967b), "Statistical Appendix", en J. Thirsk (ed.), The Agrarian History of England and $W$ ales. Cambridge: Cambridge University Press.

Braudel, F. P., y F. SPOONER (1967), "Prices in Europe 1450 to 1750 ", en E. E. RICH y C. H. WILSON (eds.), The Cambridge Economic History of Exrope. Vol. VI: The Economy of Expanding Europe in the Sixteenth and Seventeenth Centuries, Cambridge: Cambridge University Press.

Carande, Ramón (1965), Carlos $V$ y sus Banqueros, Vol. I. Madrid, Ed. Revista de Occidente.

Cipolla, C. M. (1972), «The so-called Price Revolution: Reflections on the Italian Situation», en P. BURKE (ed.), Economy and Society in Early Modern Europe, London, Harper and Row.

Davis, R. (1973), The Rise of the Atlantic Economy, London, Weidenfeld and Nicholson.

Dominguez Ortiz, A. (1973), El Antiguo Régimen: Los Reyes Católicos y los Austrias, Madrid, Alianza Editorial.

DougHTY, Robert A. (1975), “Industrial Prices and Inflation in Southern England, 1401-1640m, Explorations in Economic History, 12.

FISHER, D. (1989), "The Price Revolution: A Monetary Interpretation", The Journal of Economic History, $49,4$.

FLyNN, D. O. (1978), "A New Perspective on the Spanish Price Revolution: The Monetary Approach to the Balance of Paymentsw, Explorations in Economic History, 15.

FRIEDMAN, F. (1970), «A Theoretical Framework for Monetary Analysis», Journal of Political Economy, 78.

(1956), "The Quantity Theory of Money -A Restatement», en Studies in the Quantity Theory of Money, Chicago: Chicago University Press.

Gadiel, D. L., y M. E. Falkus (1969), “A Comment on the Price Revolution», Australian Economic History Review, 9.

GoOstone, J. A. (1991), «Monetary versus Velocity Interpretations of the Price Revolution: A Comments, The Journal of Economic History, 51, 1.

GoulD, J. D. (1970), The Great Debasement: Currency and the Economy in Mid-Tudor England, Oxford.

Hamilton, E. J. (1965, 2." ed.), American Treasure and the Price Revolution in Spain, 1501-1650. New York, Octagm Books.

- (1947), War and Prices in Spain, 1651-1800. Cambridge (Mass.): Harvard University Press.

MAURO, F. (1970), Le XVI' Siècle Europeen. Aspects Economiques, Paris.

MCCloskey, D. N. (1972), «Review of P. Ramsey, The Price Revolution in the Sixteeth-Centurym, Jowrnal of Political Economy, LXXX.

Miskimin, H. A. (1977), The Economy of Later Renaissance Europe, 1460-1600. Cambridge: Cambridge University Press. 
Modigliani, F. (1944), «Liquidity Preference and the Theory of Interest and Money", Econometrica, XII.

NADAL, J. (1959) «La revolución de los precios españoles en el siglo XVI», Hispania, 19.

NeF, J. U. (1965), "The Progress of Technology and the Growth of Large Scale Industry in Great Britain, 1540-1640m, en J. U. NEF (ed.), Conquest of the Material World. Cambridge.

- (1965b), "Comparison of Industrial Growth in France and England, 1540-1640", en J. U. NeF (ed.), Conquest of the Material World, Cambridge.

OuthwaITE, R. B. (1969), Inflation in Tudor and Early Stuart England. Studies in Economic History. London, MacMillan.

PARKER, G. (1974), «The Emergence of Modern Finance in Europe, 1500-1730m, en C. M. Cipolla (ed.), The Fontana Economic History of Europe: The Sixteenth and Seventeenth Centuries, Glasgow, Fontana Collins.

Phelps Brown, E. H., y Sheila V. Hopkins (1956), "Seven Centuries of the Prices of Consumables, Compared with Builders' Wage Rates, Economica, XXIII, 92.

(1957), "Wages-Rates and Prices: Evidence for Population Pressure in the Sixteenth Century", Economica, XXIV, 96.

- (1959), «Builders' Wage Rates, Prices and Population: Some Further Evidence», Economica, XXVI. 98.

Phillips, W. D., y Phillips, C. R. (1977), "The Castilian Fairs in Burgos, 1601-1604», Journal of Exropean Economic History, 6, 2.

PIEPER, R. (1987), La revolución de los precios en España (1500-1640). Sus causas y efectos. Barcelona, Ancora, S. A.-AGFA Gevaert S.A.

RAmSEY, P. (1971), The Price Revolution in the Sixteenth-Century. London, Methuen and $C o$.

Ruiz MARTiN, F. (1968), "Las finanzas españolas durante el reinado de Felipe II», Cuadernos de Historia, 2.

(1973), «Demanda y oferta bancarias (1450-1600)», Histoire économique du monde méditerranéen 1450-1650. Mélanges en l'honeur de Fernand Braudel, Toulouse.

- (1990a), Los destinos de la plata americana (siglos XVI y XVII). Universidad Autónoma de Madrid: Lección inagural del curso académico 1991-92. Madrid.

(1990b), Las finanqas de la Monarquia Hispánica en tiempos de Felipe IV (1621. 1665). Madrid, Real Academia de la Historia.

SliCHER VAN BATH, B. H. (1963), The Agrarian Economy of Western Europe: A.D. 500 1850. London, Arnold Press.

- (1960), «The rise of intensive husbandry in the Low Countries», en J. S. BromLeY y E. H. KOSSMAN (eds.), Britain and the Netherlands, London.

TAYlOR, H. W. (1968), «Price Revolution or Price Revision: The English and the Spanish Trade after 1604», en Renaissance and Modern Studies, XII.

THIRSK, J. (1967), «Farming Techniques», en J. Thirsk (ed.), The Agrarian History of England and $W$ ales. Cambridge: At the University Press.

UlloA, M. (1975), "Castilian Seigniorage and Coinage in the Reign of Phillip II", Journal of European Economic History, 4.

VAN DER WEE, H., (1963), The Growth of the Antwerp Market and the European Economy XIV-XVIth Centuries, 3 vols., París-Lovaina-La Haya.

(1975), «Prijzen en lonen als outwikkelings variabelen. Ean vergelijkend onder- 
zoek tussen Engeland en de Zuidelijke Nederlanden, 1400-1700», en Anbum offert à Charles Verlinden à l'occasion de ses trentes ans de professorat, Ghent.

- (1978), «Prices and Wages as Development Variables: A Comparison between England and the Southern Netherlands, 1400-1700", Acta Historiae Neerlandica, X.

- y T. PEETERS, (1970), "Un modele dynamique de croissance interseculaire du commerce mondial (XII ${ }^{\mathrm{e}}$ XVIII ${ }^{\mathrm{e}}$ siècles)», Annales: E.S.C., XXV.

VICENS VIVES, J. (1965), Historia económica de España. pp. 340-42. Barcelona, Ed. Vicens Vives.

WaLlersteIn, I. (1974), The Modern World System: Capitalist Agriculture and the Origins of the European World Ecomomy in the Sixteenth Century. New York.

WIEBE, Georg, (1895), Zur Geschichte der Preisrevolution des XVI aund XVII. Jabrhunders. Leipzig.

ZIMYANI, V. (1975), "A Typology of Central European Inflation in the XVIth and XVIIth Centuries», Journal of European Economic History, 4. 